Article

\title{
Estimating Agricultural Soil Moisture Content through UAV-Based Hyperspectral Images in the Arid Region
}

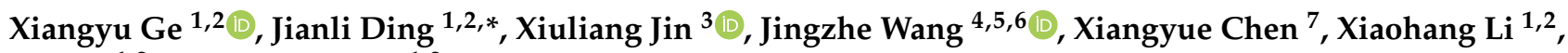 \\ Jie Liu ${ }^{1,2}$ and Boqiang Xie ${ }^{1,2}$
}

1 Key Laboratory of Smart City and Environment Modelling of Higher Education Institute, College of Resources and Environment Science, Xinjiang University, Urumqi 830046, China; gxy3s@stu.xju.edu.cn (X.G.); 1xh_xju@stu.xju.edu.cn (X.L.); liujie_0530@stu.xju.edu.cn (J.L.); 1437136910@stu.xju.edu.cn (B.X.)

2 Key Laboratory of Oasis Ecology, Xinjiang University, Urumqi 830046, China

3 Institute of Crop Sciences, Chinese Academy of Agricultural Sciences/Key Laboratory of Crop Physiology and Ecology, Ministry of Agriculture, Beijing 100081, China; jinxiuliang@caas.cn

4 MNR Key Laboratory for Geo-Environmental Monitoring of Great Bay Area, Shenzhen University, Shenzhen 518060, China; jingzhewang@szu.edu.cn

5 Guangdong Key Laboratory of Urban Informatics, Shenzhen University, Shenzhen 518060, China

6 Shenzhen Key Laboratory of Spatial Smart Sensing and Services, Shenzhen University, Shenzhen 518060, China

7 College of Atmospheric Sciences, Lanzhou University, Lanzhou 730000, China; chenxy20@lzu.edu.cn

* Correspondence: watarid@xju.edu.cn; Tel.: +86-13579265967

check for updates

Citation: Ge, X.; Ding, J.; Jin, X.; Wang, J.; Chen, X.; Li, X.; Liu, J.; Xie, B. Estimating Agricultural Soil Moisture Content through UAV-Based Hyperspectral Images in the Arid Region. Remote Sens. 2021, 13, 1562. https://doi.org/10.3390/rs13081562

Academic Editor: Luca Brocca

Received: 21 March 2021

Accepted: 14 April 2021

Published: 17 April 2021

Publisher's Note: MDPI stays neutral with regard to jurisdictional claims in published maps and institutional affiliations.

Copyright: (c) 2021 by the authors. Licensee MDPI, Basel, Switzerland. This article is an open access article distributed under the terms and conditions of the Creative Commons Attribution (CC BY) license (https:/ / creativecommons.org/licenses/by/ $4.0 /)$.

\begin{abstract}
Unmanned aerial vehicle (UAV)-based hyperspectral remote sensing is an important monitoring technology for the soil moisture content (SMC) of agroecological systems in arid regions. This technology develops precision farming and agricultural informatization. However, hyperspectral data are generally used in data mining. In this study, UAV-based hyperspectral imaging data with a resolution o $4 \mathrm{~cm}$ and totaling 70 soil samples $(0-10 \mathrm{~cm})$ were collected from farmland $\left(2.5 \times 10^{4} \mathrm{~m}^{2}\right)$ near Fukang City, Xinjiang Uygur Autonomous Region, China. Four estimation strategies were tested: the original image (strategy I), first- and second-order derivative methods (strategy II), the fractionalorder derivative (FOD) technique (strategy III), and the optimal fractional order combined with the optimal multiband indices (strategy IV). These strategies were based on the eXtreme Gradient Boost (XGBoost) algorithm, with the aim of building the best estimation model for agricultural SMC in arid regions. The results demonstrated that FOD technology could effectively mine information (with an absolute maximum correlation coefficient of 0.768 ). By comparison, strategy IV yielded the best estimates out of the methods tested $\left(R^{2}\right.$ val $=0.921, \mathrm{RMSEP}=1.943$, and $\left.\mathrm{RPD}=2.736\right)$ for the SMC. The model derived from the order of 0.4 within strategy IV worked relatively well among the different derivative methods (strategy I, II, and III). In conclusion, the combination of FOD technology and the optimal multiband indices generated a highly accurate model within the XGBoost algorithm for SMC estimation. This research provided a promising data mining approach for UAV-based hyperspectral imaging data.
\end{abstract}

Keywords: fractional-order derivatives; ensemble learning; hyperspectral data; precision agriculture

\section{Introduction}

The soil moisture content (SMC) dominates hydrothermal energy exchange, climate change, and land carbon uptake [1,2]. The limitation of SMC is the connection between atmospheric drying and hydrological responses [3]. With population increases, water scarcity will increase in arid regions. The SMC distinctly influences global food production, which is related to the achievement of the United Nations Sustainable Development Goals [4,5]. In general, SMC acts as a regulator that maintains the water and energy exchange balance between the vegetation growth and underground hydrosphere [6]. Its variability impacts crop development and alters both the canopy structure and biochemistry [7,8]. Therefore, 
the SMC ought to be monitored regularly in agricultural regions. However, it is difficult to accurately and regularly monitor soil moisture in farmland. In particular, the SMC is one of the highly variable parameters in regional precision farming, green ecology, and water resource management because the SMC is vulnerable to evapotranspiration [9-11]. Therefore, a measurement method that can accurately observe and quantify the SMC is urgently needed.

Precision agriculture requires an appropriate agricultural management program according to the specific circumstances. Its prerequisite is fast and accurate monitoring of explicit spatial information [12]. With the development of remote sensing technology, intensive spatiotemporal data inputs have replaced intensive labor in the capture of crop growth information. The tools of remote sensing include red-green-blue (RGB) sensors [13], multispectral sensors [14], hyperspectral sensors [15], and thermal sensors [16] for developed vegetation indices, sensitive bands, and imaging information. Bhatti et al. first used precision farming techniques through remote sensing technology to estimate soil nutrients and crop yields [17]. In the subsequent decades, the application of remote sensing has spread to various aspects of precision agriculture, for example in the detection of environmental stress [18], crop disease [13], and physiological crop structure during the growing season [19]. Satellite data have higher spatial resolution and shorter temporal resolution, allowing more efficient monitoring [19]. Furthermore, with the advent of unmanned aerial vehicles (UAVs), remote sensing has developed rapidly, allowing monitoring in real-time and with high precision.

The common measurement methods used for the agricultural SMC are summarized in Table 1. The oven drying technique that is commonly used to measure SMC is both time-consuming and labor-intensive [20]. For estimated SMC values, many researchers apply visible and near-infrared (Vis-NIR) spectroscopy techniques, which provide a large scientific reference for soil property characterization [21-23]. Due to the special geographical environment in arid regions, the SMC spatial heterogeneity is very strong. Although Vis-NIR technology can rapidly and nondestructively monitor soil information, it cannot achieve refined spatial expression. By providing spatial-scale information, remote sensing technology optimizes agricultural production processes. However, there has always been a restrictive relation in remote sensing technology regarding spatial, spectral, and temporal resolutions. The UAV-based technology provides finer spatial and spectral resolutions than space-borne remote sensing technology. UAV monitoring may contribute to improving the accuracy of spatiotemporal irrigation [24-26]. Particularly, UAV systems can overcome limitations of spectral and spatial resolutions when equipped with hyperspectral sensors. Additionally, studies reporting on thermal remote sensing have estimated effectively SMC values $[18,27,28]$. Thermography reflects moisture conditions in both soil and vegetation through the triangle method and crop water stress index [29]. However, the limitation of thermal remote sensing is the low spatial resolution [30].

Table 1. Summary of the soil moisture content estimation.

\begin{tabular}{cccc}
\hline Method & Advantage & Disadvantage & References \\
\hline Oven drying technique & $\begin{array}{c}\text { Regular and accurate } \\
\text { measurement of the soil water } \\
\text { content }\end{array}$ & $\begin{array}{c}\text { Labor-intensive, destructive and } \\
\text { time-consuming }\end{array}$ \\
\hline In situ sensors & $\begin{array}{c}\text { Real-time monitoring, measuring } \\
\text { the soil profile moisture }\end{array}$ & Needs multiple sensors \\
\hline Soil-water balance approach & $\begin{array}{c}\text { Good indicator of the amount of } \\
\text { irrigation water and easy to apply }\end{array}$ & $\begin{array}{c}\text { Inaccurate, vulnerable to } \\
\text { meteorological conditions }\end{array}$ \\
\hline Plant-based approaches & $\begin{array}{c}\text { Indirect estimation of plant } \\
\text { statuses to understand the effects } \\
\text { of drought stress on vegetation }\end{array}$ & $\begin{array}{c}\text { Labor-intensive, destructive, time } \\
\text { consuming, requires complex } \\
\text { instrumentation }\end{array}$ \\
\hline
\end{tabular}


Table 1. Cont.

\begin{tabular}{|c|c|c|c|}
\hline Method & Advantage & Disadvantage & References \\
\hline $\begin{array}{l}\text { Near-grounded photoelectric } \\
\text { technology }\end{array}$ & $\begin{array}{l}\text { Timely, nondestructive, and high } \\
\text { spectral resolution }\end{array}$ & $\begin{array}{l}\text { Independent point data lack a } \\
\text { spatial scale }\end{array}$ & {$[35]$} \\
\hline Space-borne photoelectric technology & Large scale, nondestructive & $\begin{array}{l}\text { Vulnerable to clouds and rain, } \\
\text { contradiction among spatial, } \\
\text { temporal and spectral resolutions }\end{array}$ & [36] \\
\hline UAV-based photoelectric technology & $\begin{array}{c}\text { Nondestructive, highly } \\
\text { maneuverable, centimeter } \\
\text { resolution, and rich photoelectric } \\
\text { information }\end{array}$ & $\begin{array}{c}\text { Requisite image analysis is still a } \\
\text { challenging task, reduced } \\
\text { precision }\end{array}$ & [22] \\
\hline Thermography & $\begin{array}{l}\text { Effectively identified SMC and } \\
\text { water stress from plant } \\
\text { temperature }\end{array}$ & Lower image resolution & [18] \\
\hline
\end{tabular}

Hyperspectral technology combines the advantages of spectroscopy and digital imaging [37]. The band range (visible-near infrared spectrum) of hyperspectral imaging has been adapted to the monitoring of crop cover areas in agricultural regions (Table 2). Previous studies have shown that the wavelength of this region can be used indirectly to estimate the water statuses of plants based on the effects of dehydration on leaf pigment characteristics [38-40]. Consequently, the SMC is assessed accurately through the canopy spectrum with the help of the UAV platform.

Table 2. Key wavebands for vegetation detection in the visible-near infrared range (400-1000 nm).

\begin{tabular}{|c|c|c|}
\hline Spectral Range (nm) & Band & Function \\
\hline $400-420$ & Violet-Blue & Strong absorption of chlorophyll \\
\hline $420-440$ & \multirow{3}{*}{ Blue } & Strong absorption of chlorophyll a and carotenoids \\
\hline $440-460$ & & Strong absorption of chlorophyll \\
\hline $460-500$ & & Strong absorption of carotenoids \\
\hline $520-540$ & Green & Strong reflection of chlorophyll and phycoerythrin absorption peak \\
\hline $540-640$ & Green and Red & Phycoerythrin absorption peak \\
\hline $\begin{array}{l}640-660 \\
660-680\end{array}$ & Red & $\begin{array}{l}\text { Strong absorption of chlorophyll and phycoerythrin absorption peak } \\
\text { Strong absorption of chlorophyll, absorption trough of most vegetation, red edge }\end{array}$ \\
\hline $680-750$ & \multirow{3}{*}{ NIR } & Red edge region \\
\hline $820-860$ & & High Reflection of vegetation and the top of red edge region \\
\hline $880-900$ & & Reflection peak of vegetation \\
\hline
\end{tabular}

Preprocessing for hyperspectral data are still a challenging task [41,42]. Hundreds of bands are measured, which increases the complexity. In practice, spectral derivative technology for pretreatment is a beneficial spectral processing approach [43] to effectively reduce redundant information and enhance prominent and sensitive spectral features $[44,45]$. However, conventional spectral derivative technology, such as first-order derivatives and second-order derivatives (integer-order derivative), cannot mine the spectral information in detail because the integer order of the derivative varies too much. Moreover, the degradation of the signal due to high-frequency noise is enhanced by high-order derivatives [46]. The fractional-order derivative (FOD) algorithm was proposed as a concept before the integer-order derivative [47]. FOD uses the interpolation ideas to insert a finer order between the original spectrum, the first-order derivative spectrum, and the second-order derivative spectrum [48]. Thus, FOD technology ensures that more features are captured. Lao et al. [49] evaluated FOD technology for mining of spectral information related to soil salt ions. Hong et al. [50] reported that the 0.75 -order reflectance was superior to first or second derivative reflectance for predicting soil organic carbon. Wang et al. [51] proposed a new approach (FOD technology) to highlight "hidden" information from Landsat data. 
Therefore, the utility of using FOD will be evaluated to preprocess hyperspectral imagery, focusing on the estimation of soil moisture based on the canopy spectrum.

Canopy spectral indices are more sensitive to changes in soil moisture because plants can physiologically control transpiration resistance according to the soil moisture stress [52,53]. The SMC at the root of the crop easily affects the photosynthetic pigments in the canopy, while the canopy spectral indices can capture the changes caused by the photosynthetic pigment $[54,55]$. In this case, the spectral bands selected by the canopy spectral indices are usually the sensitive bands for SMC. Thus, using canopy spectral indices to monitor soil moisture is useful for vegetation-covered agricultural regions. Studies have shown that the use of the three-band index $\frac{\left(R_{1429}-R_{416}-R_{1865}\right)}{\left(R_{1429}+R_{416}+R_{1865}\right)}$ may yield good results [56]. Importantly, the method may utilize the bands of photosynthetic pigments in the visible region and the absorption bands of the O-H bonds in the canopy water [57,58].

Many researchers have considered the associations between soil properties and spectral information $[59,60]$. The nonlinear regression method (machine learning strategy) is currently used to boost the prediction of soil properties [61,62]. The artificial neural network was shown to be an appropriate algorithm to quantify SMC through multispectral images [63]. Jin et al. [64] also reported that an artificial neural network model had potential high precision for estimating soil properties. However, artificial neural networks need abundant samples to drive the model. Wang et al. [65] attempted a bootstrapped framework linked to a BP neural network model and the results indicated that this method improved the performance of the soil salinity model. For limited samples, it is possible to obtain high-precision results by fully mining the data. Ensemble learning algorithms effectively reduce the prediction error by weighting and superimposing each weak learner to form a strong learner. They yield excellent results in many machine learning algorithms [66,67]. Random forest algorithms, which are representative of ensemble learning algorithms, have been shown to perform better than other algorithms in solving complex nonlinear problems [68]. However, the random forest method is prone to overfitting [69]. In recent years, the extreme gradient boosting (XGBoost) algorithm has been gradually developed and has become a potential algorithm [66,70]. XGBoost has been used to achieve good outcomes in soil digital mapping of arid regions [71]. Moreover, it has been evaluated as a better model with efficiency and robustness for estimating soil parameters from actual soil information and environmental variables [72]. In general, the XGBoost algorithm reduces variance and prevents overfitting.

Therefore, the purposes of this study are: (1) to assess the effects of FOD technology on UAV-based hyperspectral data; (2) to analyze the capacity of MI for important spectral information; and (3) to estimate the SMC using optimal XGBoost models.

\section{Materials and Methods}

\subsection{Study Area and Data Collection \\ 2.1.1. Study Area}

The study area was in Fukang City, Xinjiang Uygur Autonomous Region (Xinjiang) $\left(87^{\circ} 51^{\prime} 15^{\prime \prime} \mathrm{E}, 44^{\circ} 21^{\prime} 14^{\prime \prime} \mathrm{N}\right)$. The study area is in the oasis transition zone, the northern part of which is the Gurbantunggut Desert. This area is characterized by a temperate continental desert climate with an average annual precipitation of $220 \mathrm{~mm}$, a frost-free period of $176 \mathrm{~d}$ throughout the year, an average annual temperature of $7.1^{\circ} \mathrm{C}$, an extreme maximum temperature of $41.5^{\circ} \mathrm{C}$, and an extreme minimum temperature of $-37^{\circ} \mathrm{C}$. In particular, the precipitation is unevenly distributed. The annual average precipitation is $323 \mathrm{~mm}$ in the southern mountains, $186 \mathrm{~mm}$ in the central plain, and $145 \mathrm{~mm}$ in the northern desert. Nevertheless, Fukang City is an important base for the production of grains, premium vegetables, and special crops. It provides many agricultural and sideline products for Urumqi, which is the provincial capital city. The main crop planted in the study area is winter wheat, and the harvesting frequency is one harvest per year. The soil types according to the Food and Agriculture Organization (FAO) are calcisol and solonchak [73]. 


\subsubsection{Soil Moisture Content Measurement}

For the field scale, grid sampling was adopted as the main strategy according to the previous studies [74]. In April 2018, 70 points were selected through sampling cells $(0.5 \mathrm{~m} \times 0.5 \mathrm{~m})$ for uniform data collection, in which the surveys were executed simultaneously via UAVs. The plant residue and gravel were removed from the top layer, after which the topsoil (top $10 \mathrm{~cm}$ ) could be sampled. To make each sample representative, four soil subsamples were collected from four corners of $0.5 \mathrm{~m} \times 0.5 \mathrm{~m}$ plant-centered quadrats and thoroughly commixed. Then, a small soil sampler was used to collect a portion of topsoil from each sample. The soil samples were rapidly sealed in aluminum boxes. Every sampling position was recorded using GPS (LT500T, CHC Navigation Technology Co. Ltd. Shanghai, China). The accuracy of GPS is approximately $1 \mathrm{~m}$. The SMC was measured through the thermogravimetric technique (oven drying). This technique is the standard method for measuring SMC. With this technique, the weights of wet soil samples were measured first, then the wet soil samples were dried in the oven $\left(105^{\circ} \mathrm{C}, 48 \mathrm{~h}\right)$ and weighed. The differences between the two weights were calculated as the SMC.

\subsubsection{Hyperspectral Imaging Measurement}

The UAV field overflights were conducted before the soil sampling (Figure 1). The UAV platform was a DJI Matrice 600 Pro (Shenzhen Dajiang Innovation Technology Co., Ltd., Shenzhen, China) and the airborne hyperspectral imaging spectrometer was a Headwall Nano-Hyperspec hyperspectral sensor (Headwall Photonics Inc., Bolton, MA, USA) (Table 3). The hyperspectral imaging spectrometer has the following specifications: a band range of 400-1000 nm, a spectral resolution of $6 \mathrm{~nm}$, a resampling interval of $2.2 \mathrm{~nm}$, and 271 spectral bands [22]. When the flight altitude was $100 \mathrm{~m}$, the spatial resolution of the obtained image was $4 \mathrm{~cm}$. In the experiment, the study area had not been affected by rainfall for the past week. The day of the field operation was 17 April 2018. During this period, the area was in the "green-up" time for winter wheat, which is a period during which the crop is highly affected by soil moisture. The average plant height for winter wheat was approximately $20 \mathrm{~cm}$, while the vegetation coverage was dense. The hyperspectral data were obtained over the field at 15:00 (UTC/GMT+ 08:00) in a sunny, windless, obstruction-free environment. Operationally, the dark current correction and whiteboard calibration strategy was utilized [22]. The purpose of dark current is to reduce the residual current, which flows through a photo-sensible device when the sensor is not receiving incident radiation [75]. The purpose of this strategy is to convert the signal to the target's reflectivity and reduce the noise. To calibrate a drone image, the five control points were laid in the four corners and center of the drone captured area and recorded geographic information. Furthermore, the hyperspectral data postprocessing and orthorectification were conducted through Hyperspec ${ }^{\circledR}$ III (version 3.1) and SpectralView ${ }^{\circledR}$ (version 3.1) software. The Savitzky-Golay filter (S-G; second-order polynomial smoothing and five-band window width) smoothed, processed image was used as the base image (order $=0$, original image). The S-G procedures in this study were all performed in MATLAB R2016b (MathWorks, Natick, MA, USA). 

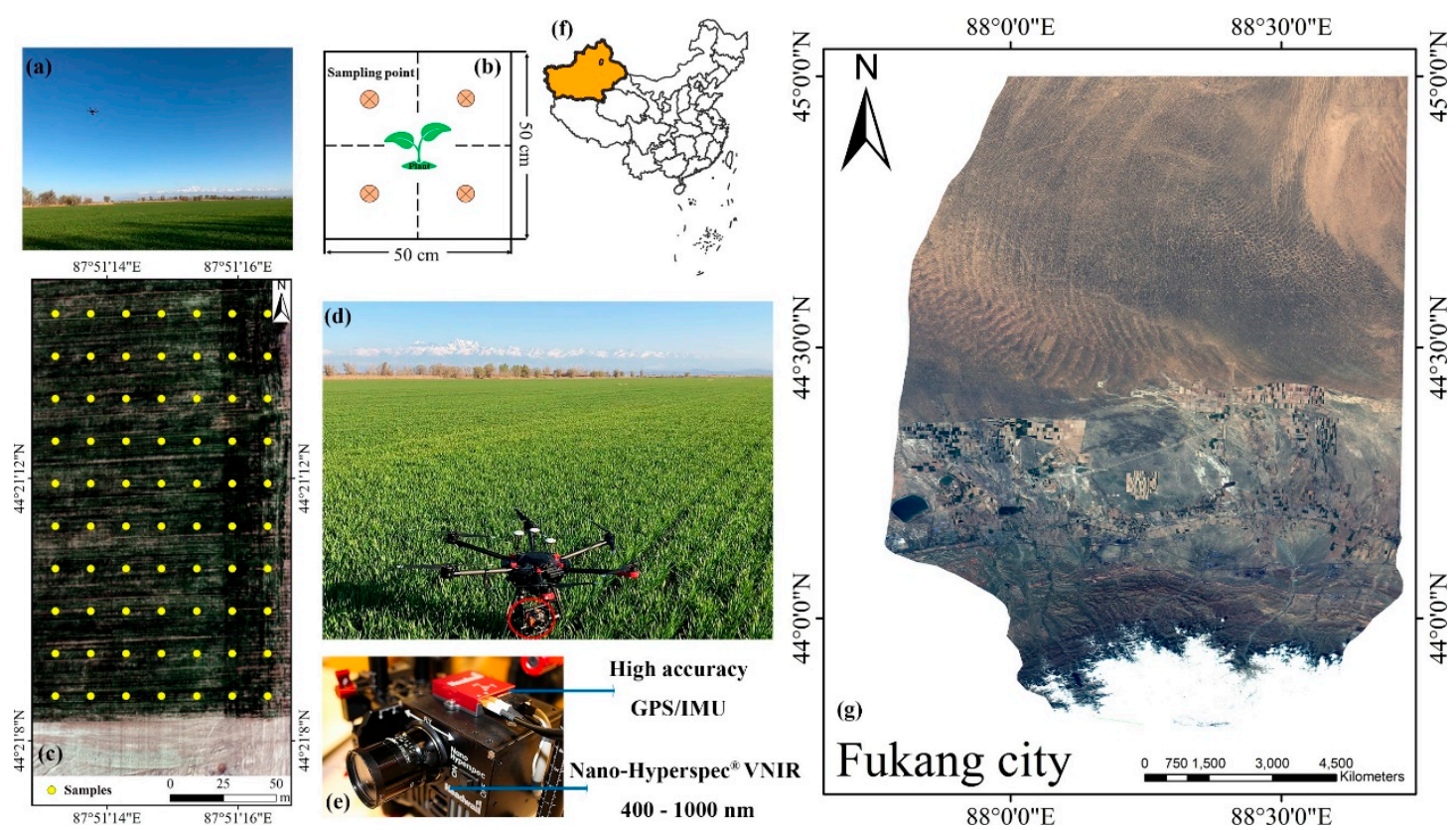

Figure 1. Overview of the study area and sampling: (a) application of the UAV; (b) four-point method of sampling; (c) sample point distribution; (d) UAV platform and airborne hyperspectral imaging sensor; (e) hyperspectral imaging sensor; (f) Xinjiang's position in China; (g) geographical location of Fukang City.

Table 3. The technical specifications of the UAV.

\begin{tabular}{|c|c|c|}
\hline Details & Items & Specifications \\
\hline \multirow{5}{*}{ Drone } & Version & DJI MATRICE 600 PRO \\
\hline & Weight & $10 \mathrm{~kg}$ \\
\hline & Dimensions & $\begin{array}{l}1668 \mathrm{~mm} \times 1518 \mathrm{~mm} \times 727 \mathrm{~mm} \text { with } \\
\text { propellers, frame arms and GPS mount } \\
\text { unfolded (including landing gear) }\end{array}$ \\
\hline & Max speed & $65 \mathrm{~km} / \mathrm{h}$ \\
\hline & Flight control system & A3 Pro \\
\hline \multirow{7}{*}{ Hyperspectral camera } & Camera & $\begin{array}{l}\text { Headwall Nano-Hyperspec } \\
\text { hyperspectral sensor }\end{array}$ \\
\hline & Dispersion/Pixel & $2.2 \mathrm{~nm} /$ pixel \\
\hline & Wavelength range & $400-1000 \mathrm{~nm}$ \\
\hline & FWHM Slit Image & $6 \mathrm{~nm}$ \\
\hline & Spectral bands & 271 \\
\hline & Spatial bands & 640 \\
\hline & Max Frame Rate & $300 \mathrm{~Hz}$ \\
\hline \multirow{4}{*}{ GIMBAL } & Version & DJI RONIN-MX \\
\hline & Controlled Rotation Range & $\begin{array}{l}\text { Pan axis control: } 360^{\circ} \\
\text { Tilt axis control: }+45^{\circ} \text { to }-135^{\circ} \\
\text { Roll axis control: } \pm 25^{\circ}\end{array}$ \\
\hline & Angular Vibration Range & $\pm 0.02^{\circ}$ \\
\hline & Operating environment & $-15^{\circ} \mathrm{C}-50^{\circ} \mathrm{C}$ \\
\hline \multirow{2}{*}{ Remote Control } & Operating Frequency & $2.400-2.483 \mathrm{GHz}$ \\
\hline & Max Operating Distance & $5 \mathrm{~km}$ \\
\hline Battery & Supported Battery Configurations & TB48S \\
\hline
\end{tabular}




\subsection{FOD Strategy}

In the past few decades, the theory of FOD has been widely used in mathematical analysis. In general, integer-order derivatives (IODs) (such as first-order derivatives and second-order derivatives) in Euclidean space have been extended to FODs, which can calculate discretional-order derivatives (noninteger). Fractional derivative theory in Euclidean space is regarded as an effective method in signal processing and dispersion processing [76]. The FOD generally has three definitions, including the Caputo, RiemannLiouville, and Grünwald-Letnikov (G-L) definitions. Of these, the G-L definition is the most appropriate method for image processing because it avoids the complicated Cauchy equation, which the other definitions use. Many researchers have used the G-L-based fractional theory to work with the fractal question because of the geometric and physical meaning of the FOD method [77,78]. The geometric meaning of FOD is a generic slope for a function curve. The physical meaning is fractional flow and generalized amplitudeand-phase modulation [76]. Generally, the spectrum of an object is regarded as a physical photoelectric signal. FODs enable continuous interpolation among IODs to improve model accuracy and performance in the field of linear spectroscopy [79]. Moreover, in previous research, the G-L-based FOD was considered to be the most effective among three definition algorithms in the one-dimensional spectrum [46,51]. Related research also supports the use of this method $[80,81]$. A definition of the G-L-based FOD is:

$$
{ }_{a}^{G} D_{b}^{v s(x)} \triangleq \lim _{h \rightarrow 0} h^{-v}(-1)^{m} \sum_{m=0}^{n-1} \frac{\Gamma(v+1)}{\Gamma(m+1) \Gamma(v-m+1)} s(b-m h)
$$

where the interval of $s(b)$ is $[a, b] ; h$ is the step length and $h=(b-a) /(n)$; and the Gamma function is $\Gamma(\tau)=(\tau-1)$ !. Here, $v=0.0$ indicates the original signal, $v=1.0$ indicates first-order derivatives, and $v=2.0$ indicates second-order derivatives. The FOD method has boundedness, which is $\left|D^{v s(x)}\right|=\left|s^{(v)}(x)\right|<\infty$. It also has continuity, which is $\log _{v_{1} \rightarrow v_{0}} D^{v_{1} s(x)}=D^{v_{2} s(x)}, v_{1}, v_{2} \in \mathbb{R}$.

In this case, the spectral resolution of hyperspectral data are $2.22 \mathrm{~nm}$ and $h$ is set to 1 . Based on the above description, Equation (1) was converted to:

$$
\begin{array}{r}
\frac{d^{v} f(x)}{d x^{v}} \approx f(x)+(-v) f(x-1)+\frac{(-v)(-v+1)}{2} f(x-2) \\
+\cdots \frac{\Gamma(-v+1)}{\Gamma(m+1) \Gamma(-v-m+1)} f(x-m)
\end{array}
$$

The FOD of hyperspectral data was calculated based on Equation (2) in MATLAB $\mathrm{R} 2016 \mathrm{~b}$. The step length was set as 0.1 from the order of 0.0 to 2.0.

Hyperspectral imaging data have spectral representation and image representation. It is important to jointly consider the image and spectral information contained in the hyperspectral data. In this study, the image quality and the relationship between the spectrum and SMC were considered to evaluate the effects of hyperspectral data preprocessed by FOD technology. Three image quality metrics-the peak signal-to-noise ratio (PSNR) [82], structural similarity index (SSIM) [83], and naturalness image quality evaluator (NIQE) [84] — evaluated the image quality after FOD processing.

(1) The PSNR is usually used to measure image quality. It is the ratio of maximum possible power to the power of corrupting noise on an image and is defined as [82]:

$$
\begin{gathered}
M S E=\frac{1}{N \times M} \sum_{i=1}^{N} \sum_{j=1}^{M}[P(i, j)-O(i, j)]^{2} \\
P S N R=10 \log _{10}\left(\frac{\max ^{2}}{M S E}\right)
\end{gathered}
$$


where $N \times M$ indicates the image size; $P(i, j)$ and $O(i, j)$ refer to the pixel value of preprocessed image and original image, respectively; and max is the maximum possible pixel value.

(2) The SSIM is consistent with human visual perception when extracting structural information in a scene. The SSIM mainly evaluates image quality through luminance, contrast, and structure. The SSIM is calculated by Equation (5):

$$
\operatorname{SSIM}(x, y)=\frac{\left(2 \alpha_{x} \alpha_{y}+C_{1}\right)\left(2 \beta_{x y}+C_{2}\right)}{\left(\alpha_{x}^{2}+\alpha_{y}^{2}+C_{1}\right)\left(\beta_{x}^{2}+\beta_{y}^{2}+C_{2}\right)}
$$

where $\alpha_{x}$ and $\alpha_{y}$ denote the mean intensities of the original image and preprocessed image, respectively; and $\beta_{x}$ and $\beta_{y}$ are their standard deviations. Here, $\beta_{x y}$ is the covariance between them and $C_{1}$ and $C_{2}$ are constants.

(3) The NIQE calculates the quality of a preprocessed image by comparing the distance between the multivariate Gaussian model of the original natural image and the multivariate Gaussian model of the preprocessed image. More details are given in [84].

Generally, the PSNR and SSIM are considered as full-reference quality metrics, while the NIQE is a no-reference quality metric [84]. Higher image quality results in lower NIQE values but higher PSNR and SSIM values. The three image quality metrics were conducted in MATLAB R2016b.

Moreover, the theory of gray relational analyses (GRA) was adopted to appraise the effect of the FOD on the spectrum [51]. GRA is a systematic analysis method for determining the nonlinear relationship between object and system parameters [64]. Another advantage of GRA is the degree of freedom on data, which are unrestricted by the sample type and statistical characteristics $[51,85]$. This algorithm was conducted as follows:

$$
\xi_{i j}=\frac{\min _{i}\left|y_{0 j}-y_{i j}\right|+\rho \max _{j}\left|y_{0 j}-y_{i j}\right|}{\left|y_{0 j}-y_{i j}\right|+\rho \max _{i} \max _{j}\left|y_{0 j}-y_{i j}\right|}
$$

where $\xi_{i j}$ is the gray relational coefficient and $\left|y_{0 j}-y_{i j}\right|$ refers to the absolute difference between the sequence of the SMC and the sequence of spectral reflectance. Here, $\rho$ is the distinguishing coefficient; usually the $\rho$ value is 0.5 . The gray relational grade (GR) is calculated as follows:

$$
G R_{i}=\frac{1}{N} \sum_{i=1}^{N} \omega_{i} \xi_{i j}
$$

where $N$ is the number of the sequences of spectral reflectance and $\omega_{i}$ represents the weight factor. The GR was calculated in MATLAB R2016b.

In this study, the original image, first- and second-order derivatives, and FOD technology were compared to mine the appropriate preprocessing method.

\subsection{Strategy}

The Pearson correlation coefficient was used to reflect the correlation between the SMC and the spectrum [79]. In general, the correlation coefficient between a single band and the SMC is one-dimensional information [21]. The spectral index composed of two spectral bands is a better representation than a single band and includes the difference index (DI), ratio index (RI), and the normalized difference index (NDI). The calculation is usually based on Equations (8)-(10):

$$
\begin{gathered}
\operatorname{DI}\left(R_{\lambda 1}, R_{\lambda 2}\right)=R_{\lambda 1}-R_{\lambda 2} \\
\operatorname{RI}\left(R_{\lambda 1}, R_{\lambda 2}\right)=R_{\lambda 1} / R_{\lambda 2} \\
\operatorname{NDI}\left(R_{\lambda 1}, R_{\lambda 2}\right)=\left(R_{\lambda 1}-R_{\lambda 2}\right) /\left(R_{\lambda 1}+R_{\lambda 2}\right)
\end{gathered}
$$

where $R_{\lambda 1}$ and $R_{\lambda 2}$ are the spectral reflectance of $\lambda 1$ and $\lambda 2$, respectively, which were arbitrarily acquired within the operating range of the hyperspectral sensor (400-1000 nm). 
Referring to the conceptual framework published by [86], a third band $\left(\lambda_{3}\right)$ was added to construct the three band indices based on Equations (8), (9), and (10), because multiple independent bands increase the potential for high precision. The multiple-band synthesis information is presented by a multidimensional map of the correlation coefficients between the spectral index and SMC. MI formulas (11)-(20) calculated each band within a range of 400-1000 nm. These formulas are derived from published articles [87,88]. From the results, we could select the most sensitive band combination through the maxima of the correlation coefficient between the indices and the SMC. From the spectral parameters, we could maximize the sensitivity of the soil attributes.

$$
\begin{gathered}
\mathrm{MI}_{1}=R_{\lambda 1} /\left(R_{\lambda 2} \times R_{\lambda 3}\right) \\
\mathrm{MI}_{2}=R_{\lambda 1} /\left(R_{\lambda 2}+R_{\lambda 3}\right) \\
\mathrm{MI}_{3}=\left(R_{\lambda 1}-R_{\lambda 2}\right) /\left(R_{\lambda 2}+R_{\lambda 3}\right) \\
\mathrm{MI}_{4}=\left(R_{\lambda 1}-R_{\lambda 2}\right) /\left(R_{\lambda 2}-R_{\lambda 3}\right) \\
\mathrm{MI}_{5}=\left(R_{\lambda 2}+R_{\lambda 3}\right) / R_{\lambda 1} \\
\mathrm{MI}_{6}=\left(R_{\lambda 1}-R_{\lambda 2}\right) /\left[\left(R_{\lambda 1}-R_{\lambda 2}\right)-\left(R_{\lambda 1}-R_{\lambda 3}\right)\right] \\
\mathrm{MI}_{7}=\left(R_{\lambda 1}-R_{\lambda 2}\right)-\left(R_{\lambda 2}-R_{\lambda 3}\right) \\
\mathrm{MI}_{8}=\left(R_{\lambda 2} \times R_{\lambda 3}\right) / R_{\lambda 1} \\
\mathrm{MI}_{9}=R_{\lambda 1}{ }^{2}+R_{\lambda 2}{ }^{2}+R_{\lambda 3}{ }^{2} \\
\mathrm{MI}_{10}=\sqrt{R_{\lambda 1}+R_{\lambda 2}+R_{\lambda 3}}
\end{gathered}
$$

The values in the slice contour map were the correlations between the MIs and SMC, and the program was applied in MATLAB R2016b.

\subsection{XGBoost}

XGBoost is a gradually rising ensemble learning method that is considered to be a gradient boosting library with scalability and flexibility [89]. Similar to gradient boosting machines, each tree (weak learner) of XGBoost gradually participates in the previous weak learner model [66]. XGBoost implements the second-order Taylor expansion on the loss function to find the optimal solution. Moreover, XGBoost has unique advantages. For instance, a regularization technique borrowing from the RF algorithm reduces overfitting and shortens the calculation costs [71]. It possesses customizable objective functions and more effective tree pruning mechanisms. Variable importance is vital feedback for XGBoost. Variable importance is generally used for characterizing datasets by uncovering the interplays among predictive variables. As a filter, it identifies prominent predictors and removes irrelevant predictors. The detailed introduction of XGBoost in [90] provides more information. The xgboost package in R software was selected for the XGBoost model in this study.

\subsection{Model Evaluation and Strategies}

The sample partitioning used a joint $\mathrm{x}-\mathrm{y}$ distance (SPXY) algorithm [91] to conduct partitioning, which included 50 samples and a validation set containing 20 samples. In this study, four strategies were compared to verify the optimal strategy (Table 4). Strategy I: All bands of the original image (order $=0$ ) participated in the XGBoost model to estimate the SMC. Strategy II: The variables involved in the estimation model were all bands of the images processed by the first- and second-order derivatives (order $=1$ and 2). Strategy III: The model variables were composed of all bands of the image processed by FOD (order $=0.1-0.9$ and 1.1-1.9). Strategy IV: Under the optimal pretreatment scheme combined with the MI scheme, the variables introduced were the optimal spectral indices obtained under the best pretreatment scheme. The full spectral bands were used as independent variables for strategy I, strategy II, and strategy III. All MIs were considered 
independent variables for strategy IV. Among modeling strategies, the SMC value was the response variable. The model was constructed using the calibration set and the validation set was verified independently. The three indicators evaluated the performance of the models, specifically: (1) the coefficient of determination $\left(R^{2}\right)$; $(2)$ the root mean square errors (RMSE); and (3) the ratio of the performance to the deviation (RPD). The related formulas are elaborated in [92,93]. In this study, according to relevant researchers [93-96], the RPD divided results into three classes: category I (RPD > 2.0), with excellent predictability; category II $(1.4<\mathrm{RPD}<2.0)$, with moderate predictability; and category III $(\mathrm{RPD}<1.4)$, with poor predictability. Models with higher $R^{2}$ and RPD values and smaller RMSE values are better. Furthermore, this study introduces scatter points and the Taylor diagram [97]. Notably, these methods efficiently portray the performance of the model and its statistical characteristics.

Table 4. Modeling strategy and description.

\begin{tabular}{cc}
\hline Modeling Strategies & Method \\
\hline Strategy I & The original image (order $=0$ ) \\
Strategy II & The first- and second-order derivatives (order $=1$ and 2) \\
Strategy III & The FOD (order $=0.1-0.9$ and $1.1-1.9$ ) \\
Strategy IV & The optimal pretreatment scheme combined with the MI scheme \\
\hline
\end{tabular}

\section{Results}

\subsection{Descriptive Statistics}

To identify the rationality of the sample division, the statistical distributions of the dataset for the entire set, calibration set, and validation set were assessed and illustrated in Figure 2. Overall, the sampling resulted in a mean of $24.45 \%$ and a standard deviation (SD) of $5.37 \%$. The environment of the area in which crops were planted near the desert was a major influence, resulting in a relatively high SD value. The mean SMC values for the calibration and validation sets were $24.87 \%$ and $23.39 \%$, respectively. The SD is usually understood as the degree of dispersion of the sample and the SD of the entire set was high, which may have been caused by the uneven spatial distribution of the SMC. Additionally, all datasets were normal distributions with similar statistical characteristics. The partitioning of the SPXY algorithm yields an analogous statistical distribution. In confirming valuable samples, potentially biased estimates were reduced as far as possible. Consequently, the two subsets were representative of the data as a whole.

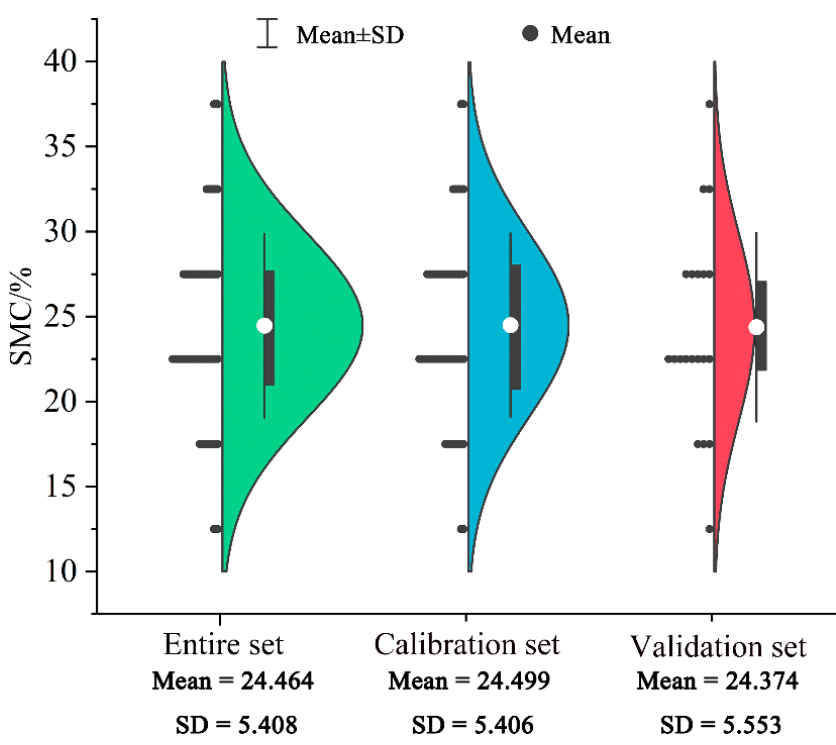

Figure 2. SMC samples and their descriptive statistics (the colored areas are the kernel density distributions of the different sets). 


\subsection{The Evaluation of the FOD Strategy}

3.2.1. Varying Features of Spectra and Images Based on the FOD

The FOD was divided into two parts, the low-frequency FOD (order $<1$ ) and the highfrequency FOD (order $>1$ ), as the results produced after FOD processing were different (Figures 3 and 4, Supplementary Figures S1 and S2).

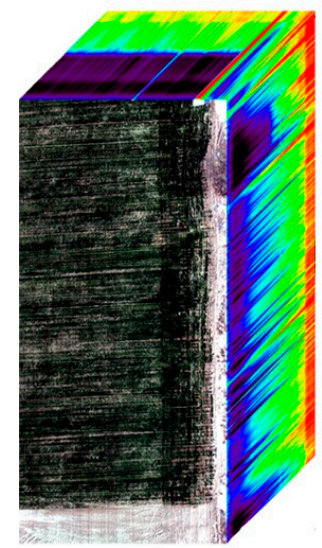

(a)

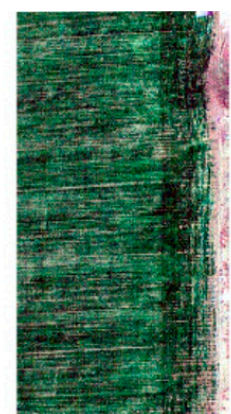

(b) 0.5 order

(d) 1.5 order

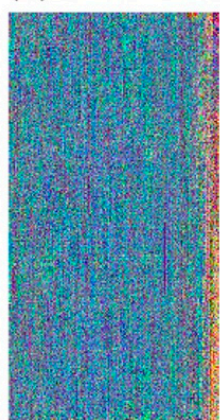

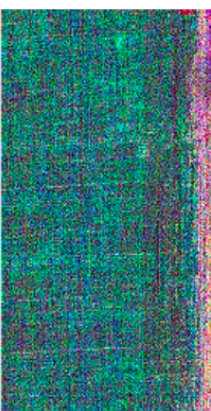

(c) 1.0 order

(e) 2.0 order

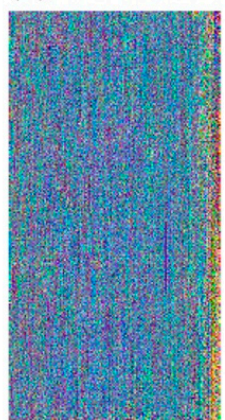

Figure 3. Results based on different FOD-preprocessed hyperspectral images. Shown here are RGB images, with the red, green, and blue bands being $R_{659}, R_{550}$, and $R_{479}$, respectively. (a) Hyperspectral image cube. (b-e) Processing results from the orders of $0.5,1,1.5$, and 2.
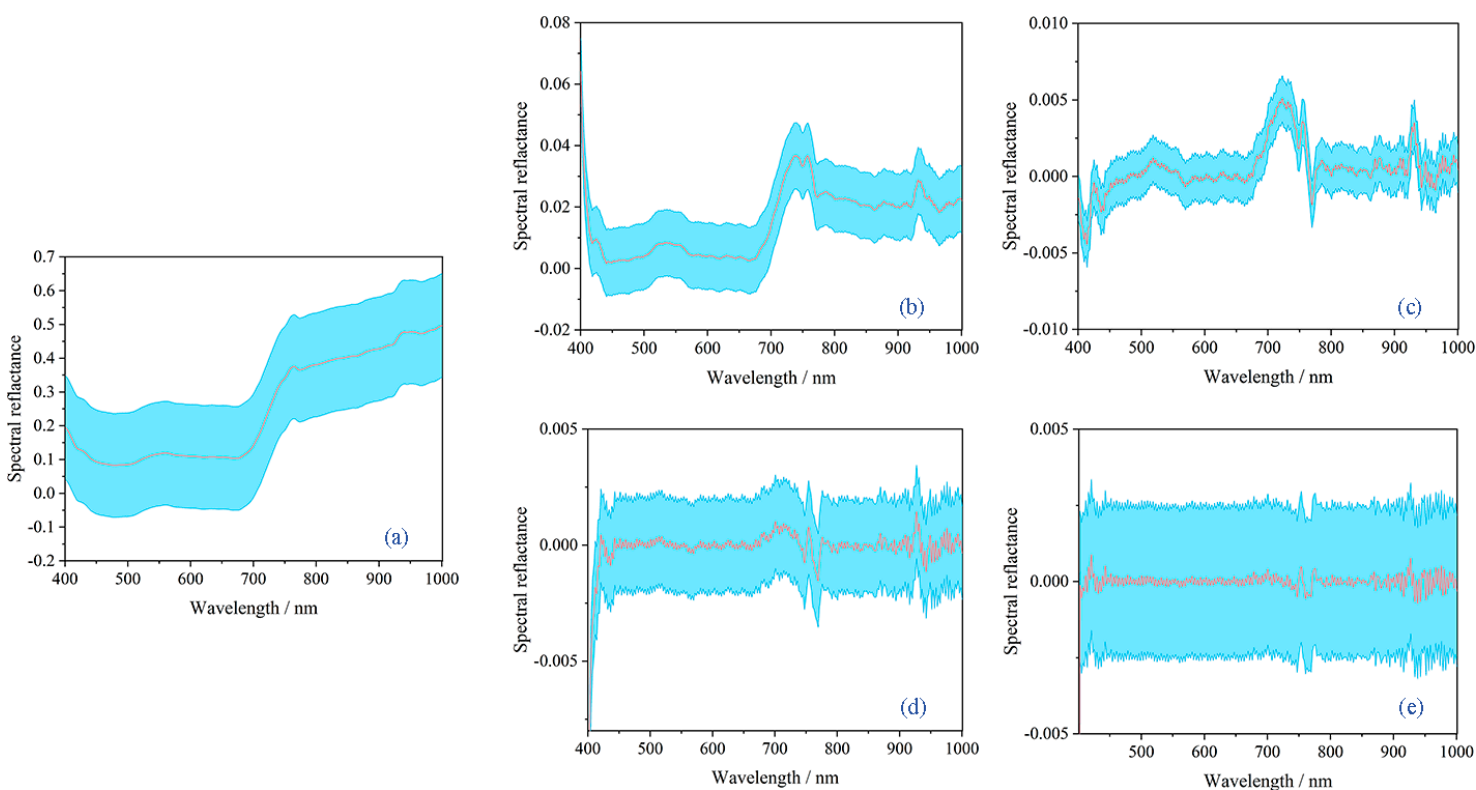

Figure 4. Results based on different FOD-preprocessed spectral curves. The red areas represent the SDs of the spectra: (a-e) the processing results from the orders of $0,0.5,1,1.5$, and 2 . 
The FOD-processed images are presented using RGB images (Figure 3 and Supplementary Figure S1). The high-frequency FOD-processed image contained considerable noise and lost its visual clarity (Figure 4 and Supplementary Figure S2). Although the low-frequency FOD was clear overall, the sharpness was also lost as the order increased. In addition to the analysis of image visualization, a comparative analysis was exerted on the spectrum. A peak near the red edge was a typical feature of the vegetation spectrum, and the FOD technique highlighted the absorption peak (Figure 4). By comparison, it was found that the spectral reflectance gradually decreased from 0.1 to 2.0 orders. The vegetation curve morphology remained relatively stable from 0.1 to 0.3 orders, and the absorption peaks from 0.4 to 1.1 orders were well defined. For the high-frequency FOD, the spectral form of the vegetation gradually disappeared and amplified the noise $(930-1000 \mathrm{~nm})$.

\subsubsection{Effects of the Spectra and Images Based on FOD}

In addition to the above, PSNR, SSIM, and NIQE were also used to assess the effects of the images based on FOD (Figure 5). Upon comparing the IOD and FOD evaluation indicators, the image quality of the IOD was poorer than that of the low-frequency FOD. The values of the PSNR and SSIM increased gradually from the orders of 0.1 to 0.4 , while the value of the NIQE decreased. However, their trends appeared to reverse the orders of 0.4 to 2 . When the order was 0.4, the values of PSNR and SSIM were the smallest and the value of NQIE was the largest. These results indicated that the image quality of the 0.4-order approach was the best. Thus, the effect of low-frequency FOD technology on image quality was more obvious than that of high-frequency FOD technology.
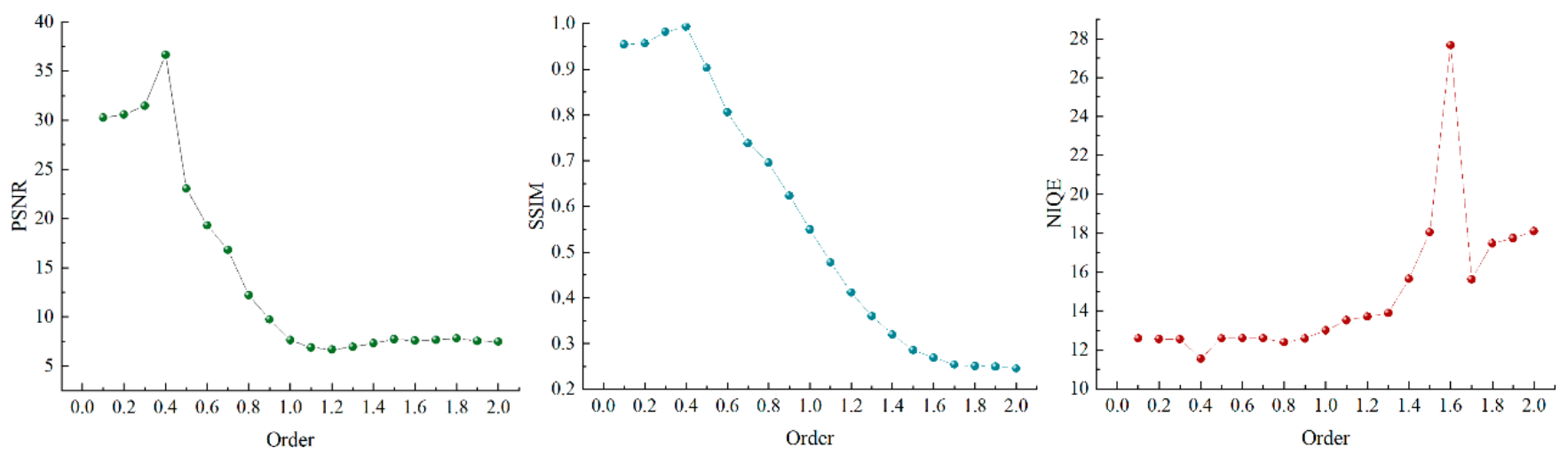

Figure 5. Three indicators used to evaluate the RGB image quality for 21 derivative orders ( 0 to 2 , with an increment of 0.1 per step).

To evaluate the effects of FOD technology on the spectrum, the absolute value of the maximum correlation $(\max |r|)$ between the SMC and spectral reflectance and the maximum gray correlation (max GR) between the SMC and the spectral reflectance for different orders were compared, respectively (Figure 6). Compared with the FOD, the values of $\max |r|$ and max GR for the second-order derivative were the lowest in the derivative processing. For the low-frequency FOD, the max $|r|$ of the 0.4-order approach was the peak value ( $\max |r|=0.768)$. Likewise, the max GR increased from the order of 0 to 0.4 as the order increased, peaking with the order of 0.4 (max GR $=0.953$ ), then decreased slightly thereafter. For the high-frequency FOD, the maximum value of max $|r|$ appeared with the order of $1.8(\max |r|=0.623)$ and the max GR had the same performance as did the max $|r|$. The maximum of the max GR was 0.953. In general, max $|r|$ can express correlation in linear terms, while max GR also reflects nonlinear relationships. The orders of 0.4 and 1.8 had the highest max $|r|$ and max GR values, indicating that the orders of 0.4 and 1.8 were optimal in this study. Moreover, a comparison between the linear and nonlinear relationships revealed that the FOD could perform data mining on imaging hyperspectral data. 

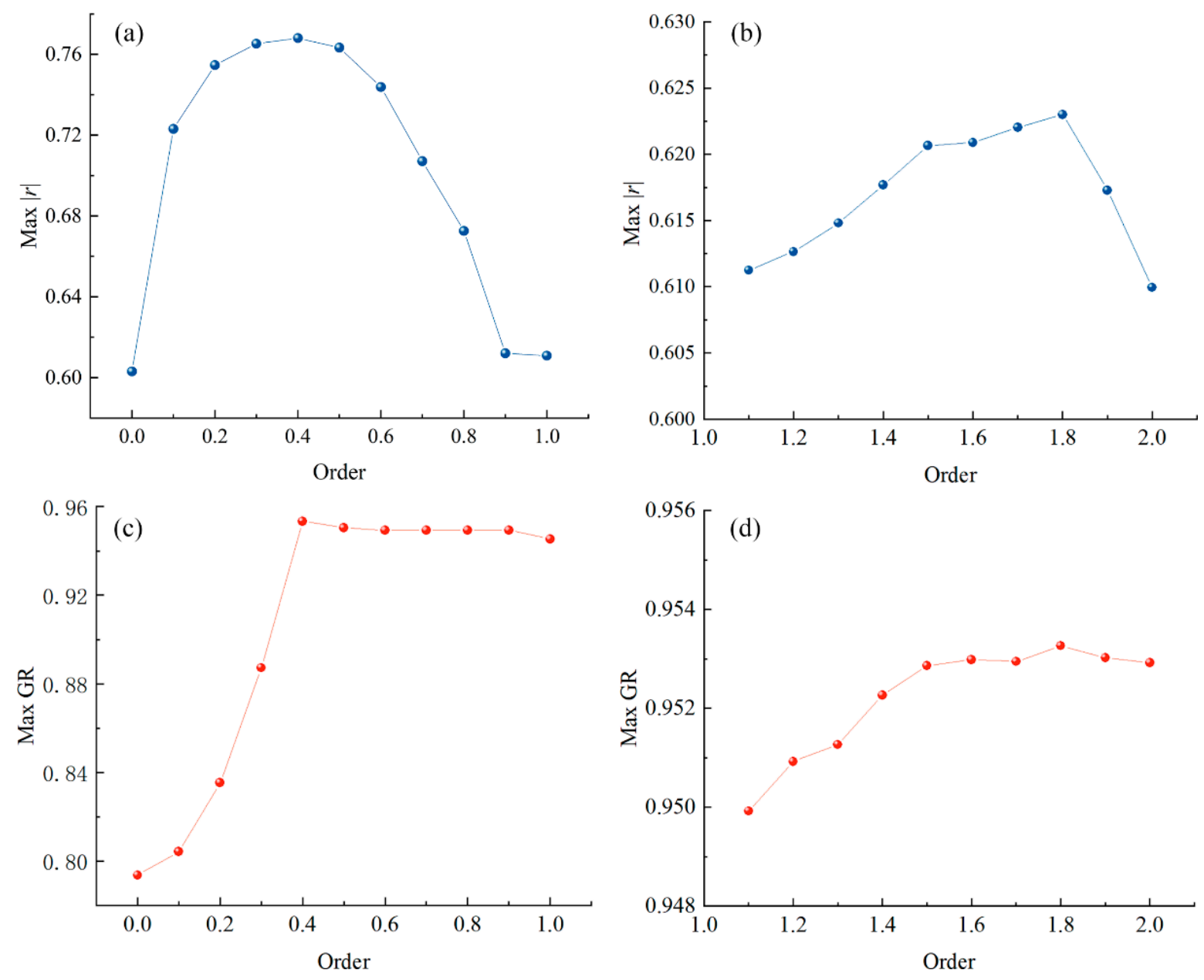

Figure 6. Max $|r|$ and max GR at 21 derivative orders (0 to 2, with an increment of 0.1 per step): (a) max $|r|$ for the orders of $0-1$; (b) max $|r|$ for the orders of 1.1-2; (c) max GR for the orders of $0-1$; (d) max GR for the orders of 1.1-2.

When analyzing hyperspectral images, FOD processing was more effective than using the IOD technique. The FOD could be regarded as providing additional detailed spectral variation information. FOD pretreatment produced more accurate relationships between the SMC and hyperspectral data compared with the original image (order $=0$ ). Compared to different FOD pretreatments, the low-frequency FOD produced superior spectral imaging data to the high-frequency FOD. The order of 0.4 was an appropriate order of FOD according to the effects on imaging hyperspectral data.

\subsection{Strategy}

To detect the capacity of MI for the highlighted important spectral information, the correlation coefficient maps between the SMC and MI1-MI10 for the appropriate order (0.4) were analyzed (Figure 7, Supplementary Figure S3 and Table 5). The optimal result was provided by MI8 (max $|r|=0.818)$. The correlation coefficient was improved by 0.215 compared to the result of the original reflectance. Compared with the value of the 0.4 order, this MI enhanced the correlation between the spectral parameters and the SMC by 0.05 . Furthermore, the value of max $|r|$ ranged from 0.770 to 0.818 , and even the minimum was slightly better than the value of the 0.4 order. These results were sufficient to demonstrate that MIs could provide additional detailed spectral parameters associated with the SMC. On balance, the bands selected by the MIs were concentrated at 446, 512, 650, and $960 \mathrm{~nm}$. 

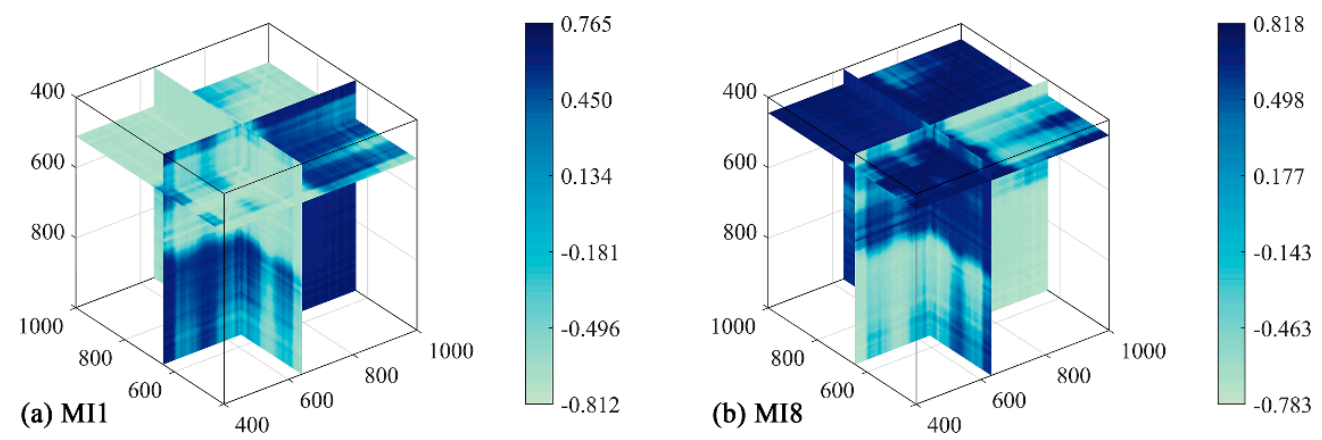

Figure 7. Optimal slice maps of the correlation coefficients between the SMC and the MI based on spectral bands. The color bars represent the correlation coefficients between the SMC and MIs, and the $\mathrm{X}$-axes, $\mathrm{Y}$-axes, and $\mathrm{Z}$-axes are the respective wavelengths that represent the three bands of the MIs. The intersections of the three slices are the absolute maxima of the correlation coefficients: (a) MI1; (b) MI8.

Table 5. The max $|\mathrm{r}|$ of MI and its selected bands.

\begin{tabular}{cccccc}
\hline MI & Max $|\boldsymbol{r}|$ & Bands of MI & MI & Max $\mid \boldsymbol{r}$ & Bands of MI \\
\hline MI1 & 0.812 & $\mathrm{R}_{644}, \mathrm{R}_{648}, \mathrm{R}_{513}$ & MI6 & 0.770 & $\mathrm{R}_{710}, \mathrm{R}_{753}, \mathrm{R}_{524}$ \\
MI2 & 0.797 & $\mathrm{R}_{446}, \mathrm{R}_{959}, \mathrm{R}_{559}$ & MI7 & 0.776 & $\mathrm{R}_{959}, \mathrm{R}_{446}, \mathrm{R}_{893}$ \\
MI3 & 0.799 & $\mathrm{R}_{446}, \mathrm{R}_{959}, \mathrm{R}_{651}$ & MI8 & 0.818 & $\mathrm{R}_{635}, \mathrm{R}_{651}, \mathrm{R}_{446}$ \\
MI4 & 0.783 & $\mathrm{R}_{710}, \mathrm{R}_{753}, \mathrm{R}_{524}$ & MI9 & 0.770 & $\mathrm{R}_{651}, \mathrm{R}_{648 \mathrm{~V}}, \mathrm{R}_{531}$ \\
MI5 & 0.803 & $\mathrm{R}_{959}, \mathrm{R}_{651}, \mathrm{R}_{446}$ & MI10 & 0.781 & $\mathrm{R}_{651}, \mathrm{R}_{448}, \mathrm{R}_{446}$ \\
\hline
\end{tabular}

\subsection{Construction and Evaluation of the Estimation Model}

To determine the effects of FOD on the performance of the model, the XGBoost model was used for estimation of the SMC based on the spectral information of the full band ( $0-2$ orders, with an increment of 0.1 at each step). The three evaluation metrics of different models are provided in Table 6 . The performance of the estimation model constructed using FOD processing was better than that of the model based on the original spectrum. Specifically, the 0.4 order XGBoost model for the predicted SMC yielded the best performance $\left(R_{\text {cal }}^{2}=0.851, \operatorname{RMSEC}=2.707, R_{\text {val }}^{2}=0.835, \operatorname{RMSEP}=2.208\right.$, and $\left.R P D=2.375\right)$. Compared with the original spectral model, the $R^{2}$ val and RPD of the 0.4 order model increased by 0.117 and 1.042, respectively. Additionally, the performance of strategy II was only slightly better than that of strategy I, but was still not as good as that of the 0.4 order model. Therefore, these results indicated that the 0.4 order was the most effective strategy.

Meanwhile, compared with the 0.4 order model, strategy IV (MI model) generated the most reliable estimation in this study, and its performance was superior to that of the 0.4 order model $\left(R_{\text {cal }}^{2}=0.921, \operatorname{RMSEC}=1.956, R_{\text {val }}^{2}=0.921, \operatorname{RMSEP}=1.943\right.$, and RPD $\left.=2.736\right)$. Furthermore, the result of the MI model was close to the measured value. The results indicated that strategy IV produced the best performance in coupling spectral parameters and the SMC.

A Taylor diagram was introduced to better illustrate the effects of each model (Figure 3.4). A good model will be closer to the red line, and the darker the color, the closer the $R^{2}$ val is to 1. It was not hard to see that the low-frequency FOD produced a model with better performance than that of the high-frequency FOD. Among the 22 models, the MI model yielded the most accurate results. Its color was dark blue and the $R^{2}$ val was the closest to 1 . The scatterplot of the measured and estimated values is portrayed in Figure 9. The scatter fitting line of the MI estimation model for the SMC was closest to the 1:1 line. Moreover, compared with strategies I, II, and III, the 0.4 order model was second only to the results of strategy IV. This result suggested that the 0.4 order model was not only superior to the original spectral model but also that the IOD (order $=1$ and 2) was inadequate. However, the other FOD models had only decent effects in general. In conclusion, the effects of the 
four modeling strategies were ranked as follows: strategy IV > strategy III > strategy II > strategy I.

Table 6. Comparisons of the XGBoost models for SMC retrieval based on different order modeling strategies.

\begin{tabular}{cccccc}
\hline Model Strategy & $\boldsymbol{R}_{\text {cal }}{ }^{2}$ & RMSEC & $\boldsymbol{R}^{\mathbf{2}}$ val & RMSEP & RPD \\
\hline 0 order & 0.719 & 3.623 & 0.718 & 3.109 & 1.333 \\
0.1 order & 0.784 & 3.181 & 0.782 & 2.566 & 2.008 \\
0.2 order & 0.794 & 3.179 & 0.790 & 2.496 & 2.044 \\
0.3 order & 0.791 & 3.090 & 0.793 & 2.461 & 2.019 \\
0.4 order & 0.851 & 2.707 & 0.835 & 2.208 & 2.375 \\
0.5 order & 0.805 & 3.076 & 0.806 & 2.573 & 1.932 \\
0.6 order & 0.780 & 3.142 & 0.790 & 2.731 & 1.547 \\
0.7 order & 0.762 & 3.279 & 0.760 & 2.774 & 1.700 \\
0.8 order & 0.781 & 3.539 & 0.757 & 3.023 & 1.525 \\
0.9 order & 0.784 & 3.268 & 0.750 & 2.828 & 1.531 \\
1 order & 0.768 & 3.518 & 0.749 & 3.257 & 1.117 \\
1.1 order & 0.754 & 3.590 & 0.727 & 3.213 & 1.277 \\
1.2 order & 0.746 & 3.577 & 0.747 & 2.944 & 1.415 \\
1.3 order & 0.758 & 3.435 & 0.748 & 3.054 & 1.479 \\
1.4 order & 0.777 & 3.123 & 0.758 & 2.834 & 1.418 \\
1.5 order & 0.781 & 2.974 & 0.759 & 3.026 & 1.147 \\
1.6 order & 0.791 & 3.533 & 0.760 & 2.922 & 1.479 \\
1.7 order & 0.795 & 2.847 & 0.771 & 2.762 & 1.415 \\
1.8 order & 0.806 & 2.684 & 0.785 & 2.704 & 1.500 \\
1.9 order & 0.780 & 3.035 & 0.762 & 3.076 & 1.049 \\
2 order & 0.751 & 2.910 & 0.743 & 3.000 & 1.226 \\
MI & 0.921 & 1.956 & 0.921 & 1.943 & 2.736 \\
\hline
\end{tabular}

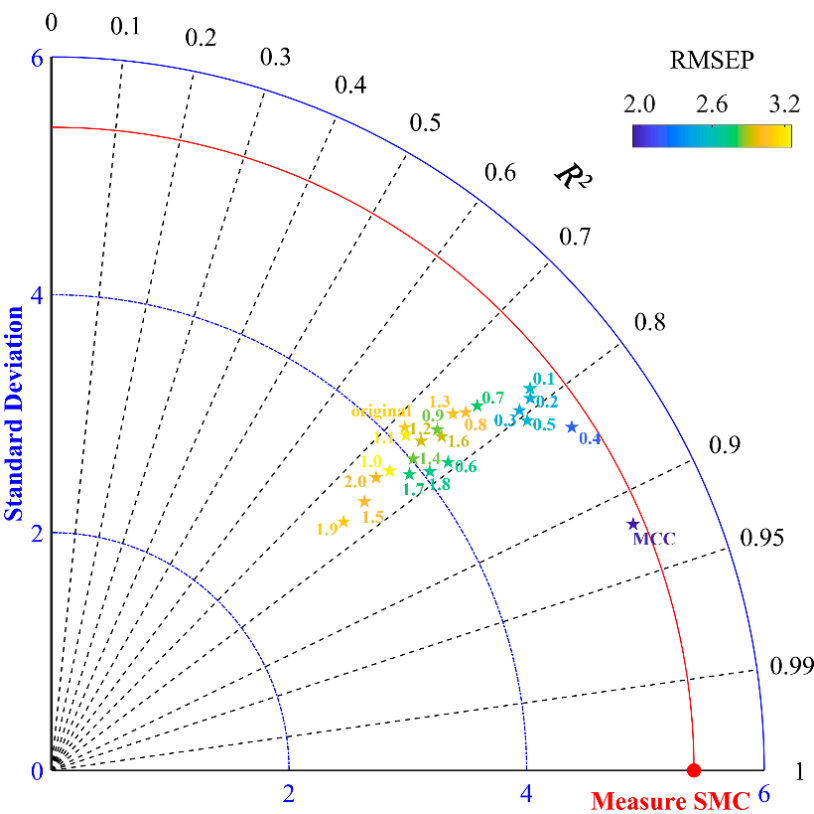

Figure 8. Taylor diagram of the estimated accuracy of each model. The black dotted line indicates $\mathrm{R}^{2}$ val, the blue line indicates the SD, and the colored stars represent the 22 models, whose colors from dark blue to deep red indicate small to large RMSEP values. The red line represents the measured SMC.

The distribution of SMC was uneven (Figure 10). There was a higher SMC in the eastern part of the farmland (west of bare land) and a lower SMC in another part. This result showed the spatial distribution of the SMC was nonstationary, even in the plot. 

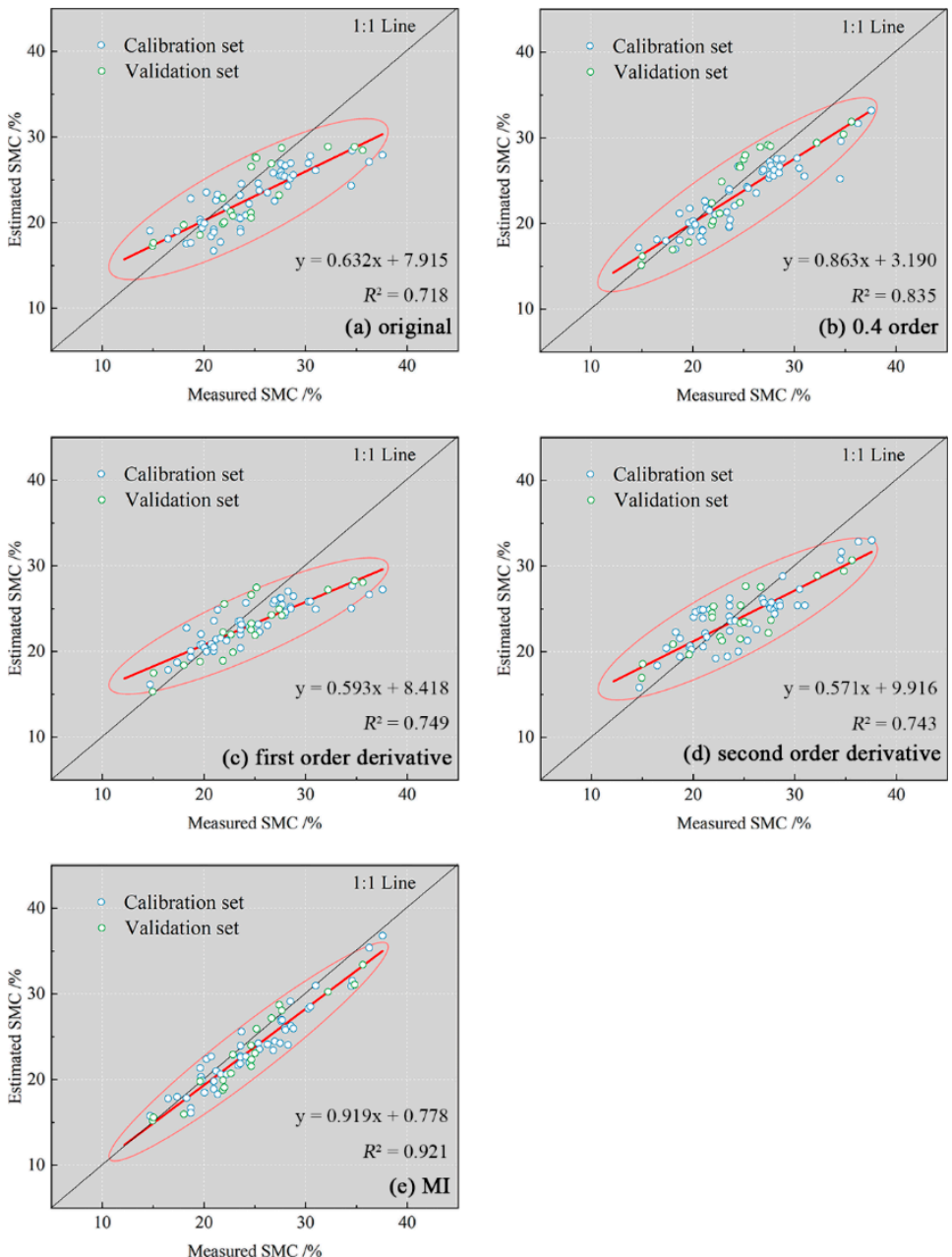

Figure 9. Scatterplots of the measured SMC and estimated SMC (representative model). The red area is a confidence ellipse of $95 \%$ confidence.

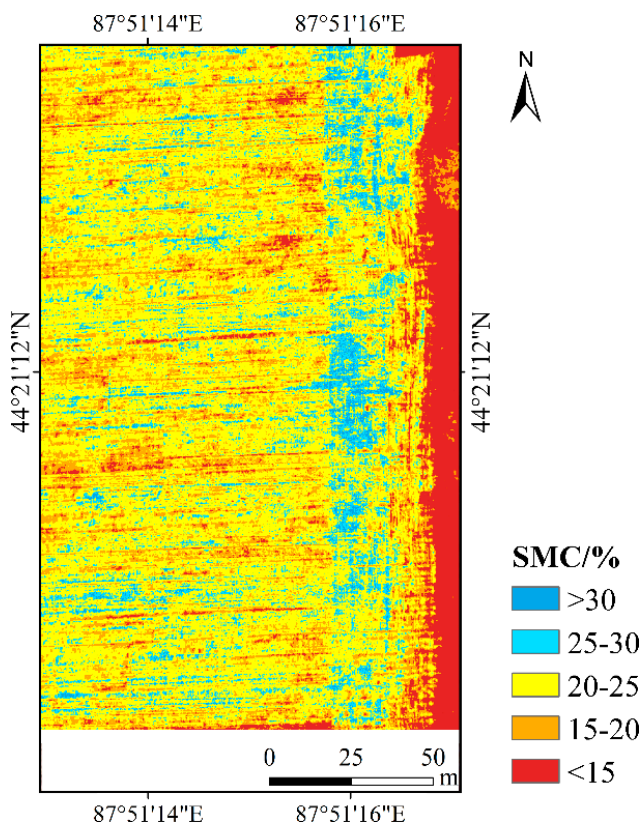

Figure 10. SMC digital soil mapping under the optimal estimation model strategy. 


\section{Discussion}

Hyperspectral sensors supply plentiful information and observation perspectives. Goran et al. reported on a UAV platform applied for daily accurate practice in agriculture and forestry [98]. Figure 3 and 4 show that UAV-based hyperspectral data had finer spatial and spectral resolutions. Such data are more conducive to serving precision agriculture projects. For example, the SMC values had extremely uneven distribution in this study (Figure 10) — consistent with the results found by Lian et al. [3] — because of water scarcity and strong evaporation in arid regions. Timely monitoring is crucial to proper irrigation. Furthermore, Ehsan et al. stated that precise measures of irrigation are urgently needed because irrigated agriculture consumes large amounts of scarce fresh water in arid regions [99]. The optimal results indicated that SMC estimations were reliable. The key to precision agriculture depends on the accuracy and availability of spatial information [12].

The spectral derivative method was adopted to deal with the multicollinearity of the spectrum $[49,50,100]$. The results showed that the effects of FOD technology for hyperspectral data combining images with spectra were significant. More importantly, this study verified that the image quality corresponded to the spectral effects when the FOD was of the order of 0.4. Consistent with the literature, this result showed that low-frequency FOD ( 0.75 order) was superior to high-frequency FOD [50]. This may have been because the features of the red edge weaken as the order increases and inherent spectral noise strengthens. This result is consistent with those of other studies [49-51,100]. Additionally, studies have shown FOD pretreatment to be better than IOD pretreatment $[100,101]$, because the IOD filters out large amounts of background information, highlighting the edge features and causing substantial information loss. Preprocessing is essential for imaging hyperspectral data with high-dimensional features. However, the second-order derivatives are not satisfactory according to image processing results, which is consistent with previous research $[22,50]$. Consequently, the FOD retained information by relying on the original characteristics.

The band importance was portrayed to confirm the rationality of constructing the estimated SMC model with high precision (Figure 11). In general, the XGBoost algorithm can provide the importance of each variable under different FOD strategies. The importance score can be used to characterize the importance of participating in the estimation model. In the low-frequency FOD, the higher importance of the band was mainly concentrated at $400-460 \mathrm{~nm}$, near $550 \mathrm{~nm}$, near $700 \mathrm{~nm}$, and near $960 \mathrm{~nm}$. For the high-frequency FOD, areas of higher importance were concentrated at approximately $400-450 \mathrm{~nm}$ and approximately $700 \mathrm{~nm}$. These bands were the strong absorption bands of chlorophyll and water in the plants $[102,103]$, whereas the chlorophyll of the crop canopy changes with the degree of drought [104]. Such changes appeared in the spectral bands that responded to different chlorophyll contents. This result was similar to the research by Yang et al. [52]. Therefore, this result indicated that the low-frequency FOD identified more sensitive spectral bands.

(a)

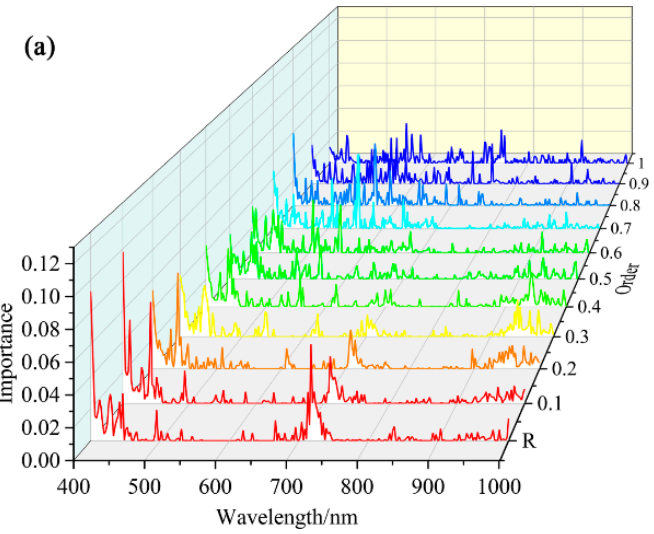

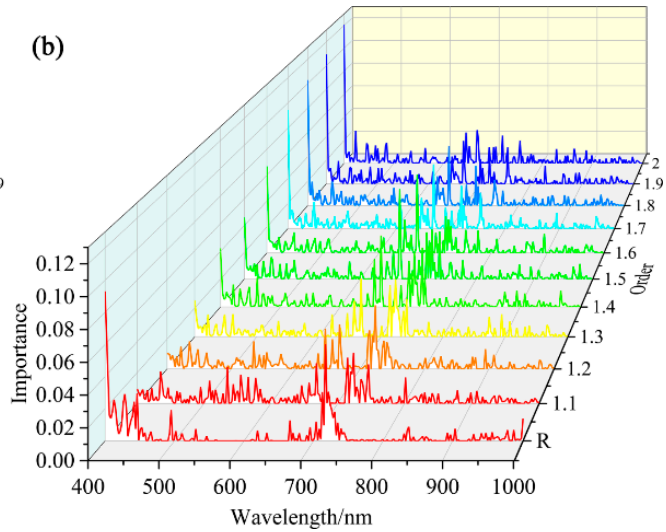

Figure 11. The importance of all bands for 21 derivative orders ( 0 to 2 , with an increment of 0.1 per step). (a) the importance within 0-1 orders, (b) the importance within 1.1-2 orders. 
The MI strategy enhanced the correlation between the spectral parameters and SMC. Such an advantage might be because of the synergy among multiple sensitive bands and noise reduction. The MIs better visualized spectral features, allowing us to explore more subtle spectral information compared to using the traditional correlation map. However, many studies have used the spectral index method while considering only two bands $[21,50,51,105,106]$. Including previous research [22], the maximum correlation between the spectral index of the two bands and the SMC was 0.773 . In comparison, the maximum correlation between MI and SMC was increased by 0.039 in this study, which might be the effect of the red-edge bands. The MI strategy may also prove useful for estimating SMC values from satellite-borne remote sensing data using the red-edge bands (such as Sentinel 2 or Sentinel 3) [87]. In addition, the MI strategy improved the modeling precision compared with other full spectral bands because the MI strategy reduced the dimensionality of the hyperspectral data and extracted the bands containing sensitive information.

In this study, an effective strategy was provided for the integration of FOD technology and MI within an XGBoost algorithm framework. Although the estimation strategy had high precision, agricultural SMC was underestimated. Comparing the measured SMC and the estimated SMC values, the mean and median of the estimated SMC values were $24.46 \%$ and $23.97 \%$, respectively (Figure 12). Similarly, the fitting line (red line) of the estimated value was also lower than the 1:1 line (Figure 9). It is generally known that it is still difficult to construct a perfect model to represent an actual object. Although machine learning algorithms try to mine data as much as possible, models are merely simplified representations of the real world. XGBoost is a leader in ensemble learning, as it uses as small a sample as possible to achieve good performance estimates [107]. Hence, XGBoost is still beneficial in estimating models and soil mapping. It is common for the estimated value to be lower than the measured value in studies of digital soil mapping because all of the processes and their interactions are not sufficiently understood, which might require more relevant information, for example multitemporal hyperspectral data. However, compared with other studies, the results of the XGBoost model are the closest to the true values $[66,89,108]$.

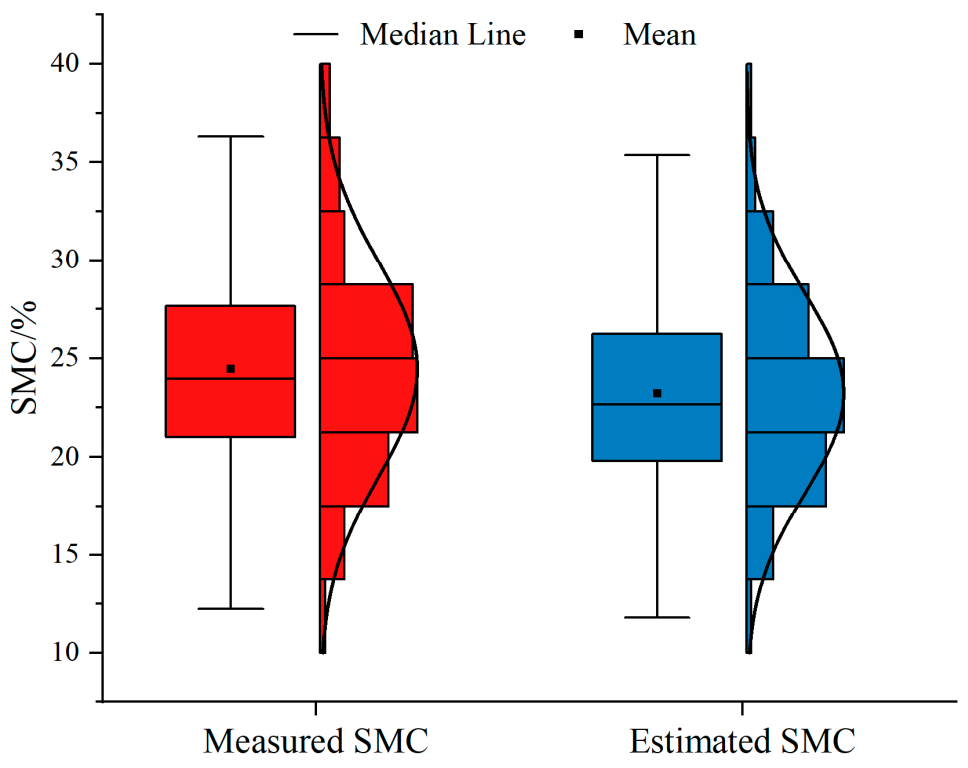

Figure 12. Boxplots of measured and estimated SMC values based on the optimal strategy.

Soil monitoring is necessary for precision agriculture, especially because the SMC has extensive spatial heterogeneity in arid regions [109]. It is noteworthy that drought and salinization may happen at the same time, because salinization is a form of aridity. Moreover, crop models [110] and thermal sensors [111] are indispensable in measuring drought stress. This will also be the focus of our further research. In recent years, merely 
considering the vegetation indices or spectroscopy information could be an appropriate method to estimate the physical and chemical properties of vegetation and soil [112,113]. To reduce errors, the calibration process should involve real-time kinematic (RTK), although the operation process involves coordinate information being recorded twice. In further studies, an ensemble framework will be built on hyperspectral and thermal data to expand the comprehensive estimation of agricultural SMC. With increasingly fragile agroecological systems, this study offers a good method for sustainable precision agricultural development. Moreover, this study provides new strategies to prevent drought disasters. Accurate agricultural management approaches will be able to better respond to the threats of increased aridity based on these results.

\section{Conclusions}

A fractional-order derivative (FOD) technique was utilized to improve the effects of imaging hyperspectral data in data mining. The plan provided a strategy with high performance for SMC estimation in arid areas under scarce data conditions. This study investigated the improvement of fractional-order derivatives of spectral imaging data, combining images with spectra in two ways. Not only was the image quality enhanced and useful information highlighted, but more significant relationships between the SMC and the spectrum were also captured. The 0.4 order yielded the lowest PSNR and SSIM values and the highest NIQE value. Compared with the original image, the first- and second-order derivative correlations with the SMC were increased by $0.165,0.157$, and 0.158 , respectively. Additionally, the gray correlation was improved by 0.159 compared to that of the original data. The MI algorithm yielded the synergistic effect of multiple sensitive bands while reducing the dimensionality of high-dimensional data. Among all spectral parameters of the MI, the MI8 performed best, with an absolute maximum correlation coefficient of 0.818. The application of the FOD method improved the accuracy of SMC estimation using hyperspectral imaging data. The 0.4 order played an important role, producing model results that were more suitable than those of the original data $\left(R_{\text {val }}^{2}=0.835, \operatorname{RMSEP}=2.208\right.$, and RPD = 2.375). Under the framework of the XGBoost algorithm, an excellent estimation model $\left(R_{\text {val }}^{2}=0.885\right.$, RMSEP $=2.145$, and RPD $\left.=2.505\right)$ was yielded by combining spectral parameters based on the order of 0.4 with the MI. In this study, the outcomes might inspire further research on precision farming management and agricultural informatization in arid regions relying on remote-sensing technology. The resulting conclusions contribute to a better understanding of the effects of FOD technology on spectral imaging data for mining.

Supplementary Materials: The following are available online at https:/ / www.mdpi.com/article / 10.3390/rs13081562/s1, Figure S1: Results based on different FOD-preprocessed hyperspectral images. Shown here are RGB images, with the red, green and blue bands being R659, R550 and $\mathrm{R} 479$, respectively. (a) is a hyperspectral image cube; (b)-(u) are the processing results from the 0.1 to 2 orders, Figure S2: Results based on different FOD-preprocessed spectral curves. The red areas represent the SDs of the spectra. (a)-(u) are the processing results from the 0 to 2 orders, Figure S3: Optimal slice maps of the correlation coefficients between the SMC and the potential $10 \mathrm{MI}$ based on spectral bands. The color bars represent the correlation coefficients between the SMC and MIs, and the $\mathrm{X}$-axes, Y-axes, and Z-axes are the respective wavelengths that represent the three bands of the MIs. The intersections of the three slices are the absolute maxima of the correlation coefficients.

Author Contributions: Conceptualization, J.D. and X.G.; methodology, X.G.; software, J.W.; validation, X.C.; formal analysis, X.G. and J.W.; investigation, X.L.; resources, J.L.; data curation, B.X.; writing-original draft preparation, X.G.; writing—review and editing, X.G. and X.J.; visualization, X.G.; supervision, J.D.; project administration, J.D.; funding acquisition, J.D. All authors have read and agreed to the published version of the manuscript.

Funding: Please add: This research was funded by the National Natural Science Foundation of China, no. 41961059 and 41771470. 
Acknowledgments: We appreciate the anonymous reviewers and editors for appraising our manuscript and for offering instructive comments. Besides, I'm especially grateful to the Communist Party of China and the Chinese people to beat the epidemic.

Conflicts of Interest: The authors declare no conflict of interest.

$\begin{array}{ll}\text { Abbreviations } \\ \text { UAV } & \text { unmanned aerial vehicle } \\ \text { SMC } & \text { soil moisture content } \\ \text { XGBoost } & \text { eXtreme Gradient Boost } \\ \text { FOD } & \text { fractional-order derivative } \\ \text { MI } & \text { multiband indices } \\ \text { RGB } & \text { red-green-blue } \\ \mathrm{R}^{2} & \text { the coefficient of determination } \\ \mathrm{R}^{2} \text { cal } & \text { the coefficient of determination about calibration } \\ \mathrm{R}^{2} \text { val } & \text { the coefficient of determination about validation } \\ \text { RMSE } & \text { the root mean square errors } \\ \text { RMSEC } & \text { the root mean square errors about the calibration set } \\ \text { RMSEP } & \text { the root mean square errors about the validation set } \\ \text { RPD } & \text { the ratio of the performance to the deviation } \\ \text { Vis-NIR } & \text { visible and near-infrared } \\ \text { IODs } & \text { integer-order derivatives } \\ \text { S-G } & \text { second-order polynomial smoothing and five-band smoothing } \\ \text { SD } & \text { standard deviation } \\ \text { G-L } & \text { Grünwald-Letnikov } \\ \text { PSNR } & \text { peak signal-to-noise ratio } \\ \text { SSIM } & \text { structural similarity index } \\ \text { NIQE } & \text { naturalness image quality evaluator } \\ \text { GRA } & \text { gray relational analyses } \\ \text { GR } & \text { gray relational grade } \\ \text { DI } & \text { difference index } \\ \text { RI } & \text { ratio index } \\ \text { NDI } & \text { normalized difference index } \\ \text { SPXY } & \text { sample partitioning used a joint x-y distance } \\ r & \text { correlation coefficient } \\ \text { max } & \text { maximum } \\ \text { min } & \text { minimum } \\ & \\ & \end{array}$

\section{References}

1. Humphrey, V.; Berg, A.; Ciais, P.; Gentine, P.; Jung, M.; Reichstein, M.; Seneviratne, S.I.; Frankenberg, C. Soil moistureAtmosphere feedback dominates land carbon uptake variability. Nature 2021, 592, 65-69. [CrossRef] [PubMed]

2. Liu, L.; Gudmundsson, L.; Hauser, M.; Qin, D.; Li, S.; Seneviratne, S.I. Soil moisture dominates dryness stress on ecosystem production globally. Nat. Commun. 2020, 11, 4892. [CrossRef] [PubMed]

3. Lian, X.; Piao, S.; Chen, A.; Huntingford, C.; Fu, B.; Li, L.Z.X.; Huang, J.; Sheffield, J.; Berg, A.M.; Keenan, T.F.; et al. Multifaceted characteristics of dryland aridity changes in a warming world. Nat. Rev. Earth Environ. 2021. [CrossRef]

4. Rockström, J.; Falkenmark, M.; Karlberg, L.; Hoff, H.; Rost, S.; Gerten, D. Future water availability for global food production: The potential of green water for increasing resilience to global change. Water Resour. Res. 2009, 45. [CrossRef]

5. Iizumi, T.; Sakuma, H.; Yokozawa, M.; Luo, J.-J.; Challinor, A.J.; Brown, M.E.; Sakurai, G.; Yamagata, T. Prediction of seasonal climate-induced variations in global food production. Nat. Clim. Chang. 2013, 3, 904-908. [CrossRef]

6. Cleverly, J.; Eamus, D.; Restrepo Coupe, N.; Chen, C.; Maes, W.; Li, L.; Faux, R.; Santini, N.S.; Rumman, R.; Yu, Q.; et al. Soil moisture controls on phenology and productivity in a semi-arid critical zone. Sci. Total Environ. 2016, 568, 1227-1237. [CrossRef]

7. Stagakis, S.; González-Dugo, V.; Cid, P.; Guillén-Climent, M.L.; Zarco-Tejada, P.J. Monitoring water stress and fruit quality in an orange orchard under regulated deficit irrigation using narrow-band structural and physiological remote sensing indices. ISPRS J. Photogramm. Remote Sens. 2012, 71, 47-61. [CrossRef]

8. Stagakis, S.; Markos, N.; Sykioti, O.; Kyparissis, A. Monitoring canopy biophysical and biochemical parameters in ecosystem scale using satellite hyperspectral imagery: An application on a Phlomis fruticosa Mediterranean ecosystem using multiangular CHRIS/PROBA observations. Remote Sens. Environ. 2010, 114, 977-994. [CrossRef] 
9. Martínez-Fernández, J.; González-Zamora, A.; Sánchez, N.; Gumuzzio, A.; Herrero-Jiménez, C.M. Satellite soil moisture for agricultural drought monitoring: Assessment of the SMOS derived Soil Water Deficit Index. Remote Sens. Environ. 2016, 177, 277-286. [CrossRef]

10. Xu, S.; Liu, Y.; Wang, X.; Zhang, G. Scale effect on spatial patterns of ecosystem services and associations among them in semi-arid area: A case study in Ningxia Hui Autonomous Region, China. Sci. Total Environ. 2017, 598, 297-306. [CrossRef]

11. Xue, J.; Guan, H.; Huo, Z.; Wang, F.; Huang, G.; Boll, J. Water saving practices enhance regional efficiency of water consumption and water productivity in an arid agricultural area with shallow groundwater. Agric. Water Manag. 2017, 194, 78-89. [CrossRef]

12. Maes, W.H.; Steppe, K. Perspectives for Remote Sensing with Unmanned Aerial Vehicles in Precision Agriculture. Trends Plant Sci. 2019, 24, 152-164. [CrossRef]

13. Jin, X.; Liu, S.; Baret, F.; Hemerlé, M.; Comar, A. Estimates of plant density of wheat crops at emergence from very low altitude UAV imagery. Remote Sens. Environ. 2017, 198, 105-114. [CrossRef]

14. Brook, A.; De Micco, V.; Battipaglia, G.; Erbaggio, A.; Ludeno, G.; Catapano, I.; Bonfante, A. A smart multiple spatial and temporal resolution system to support precision agriculture from satellite images: Proof of concept on Aglianico vineyard. Remote Sens. Environ. 2020, 240, 111679. [CrossRef]

15. Camino, C.; González-Dugo, V.; Hernández, P.; Sillero, J.C.; Zarco-Tejada, P.J. Improved nitrogen retrievals with airborne-derived fluorescence and plant traits quantified from VNIR-SWIR hyperspectral imagery in the context of precision agriculture. Int. J. Appl. Earth Obs. Geoinf. 2018, 70, 105-117. [CrossRef]

16. Bian, J.; Zhang, Z.; Chen, J.; Chen, H.; Cui, C.; Li, X.; Chen, S.; Fu, Q. Simplified Evaluation of Cotton Water Stress Using High Resolution Unmanned Aerial Vehicle Thermal Imagery. Remote Sens. 2019, 11. [CrossRef]

17. Bhatti, A.U.; Mulla, D.J.; Frazier, B.E. Estimation of soil properties and wheat yields on complex eroded hills using geostatistics and thematic mapper images. Remote Sens. Environ. 1991, 37, 181-191. [CrossRef]

18. Zhou, Z.; Majeed, Y.; Diverres Naranjo, G.; Gambacorta, E.M.T. Assessment for crop water stress with infrared thermal imagery in precision agriculture: A review and future prospects for deep learning applications. Comput. Electron. Agric. 2021, 182, 106019. [CrossRef]

19. Mulla, D.J. Twenty five years of remote sensing in precision agriculture: Key advances and remaining knowledge gaps. Biosyst. Eng. 2013, 114, 358-371. [CrossRef]

20. Pulley, S.; Collins, A.L. Sediment loss in response to scheduled pasture ploughing and reseeding: The importance of soil moisture content in controlling risk. Soil and Tillage Research 2020, 204, 104746. [CrossRef]

21. Jin, X.; Song, K.; Du, J.; Liu, H.; Wen, Z. Comparison of different satellite bands and vegetation indices for estimation of soil organic matter based on simulated spectral configuration. Agric. For. Meteorol. 2017, 244-245, 57-71. [CrossRef]

22. Ge, X.; Wang, J.; Ding, J.; Cao, X.; Zhang, Z.; Liu, J.; Li, X. Combining UAV-based hyperspectral imagery and machine learning algorithms for soil moisture content monitoring. Peer] 2019, 7, e6926. [CrossRef]

23. Guo, L.; Zhang, H.; Shi, T.; Chen, Y.; Jiang, Q.; Linderman, M. Prediction of soil organic carbon stock by laboratory spectral data and airborne hyperspectral images. Geoderma 2019, 337, 32-41. [CrossRef]

24. Gago, J.; Douthe, C.; Coopman, R.E.; Gallego, P.P.; Ribas-Carbo, M.; Flexas, J.; Escalona, J.; Medrano, H. UAVs challenge to assess water stress for sustainable agriculture. Agric. Water Manag. 2015, 153, 9-19. [CrossRef]

25. Maimaitijiang, M.; Sagan, V.; Sidike, P.; Maimaitiyiming, M.; Hartling, S.; Peterson, K.T.; Maw, M.J.W.; Shakoor, N.; Mockler, T.; Fritschi, F.B. Vegetation Index Weighted Canopy Volume Model (CVMVI) for soybean biomass estimation from Unmanned Aerial System-based RGB imagery. ISPRS J. Photogramm. Remote Sens. 2019, 151, 27-41. [CrossRef]

26. Song, Z.; Zhang, Z.; Yang, S.; Ding, D.; Ning, J. Identifying sunflower lodging based on image fusion and deep semantic segmentation with UAV remote sensing imaging. Comput. Electron. Agric. 2020, 179, 105812. [CrossRef]

27. Gerhards, M.; Schlerf, M.; Mallick, K.; Udelhoven, T. Challenges and Future Perspectives of Multi-/Hyperspectral Thermal Infrared Remote Sensing for Crop Water-Stress Detection: A Review. Remote Sens. 2019, 11. [CrossRef]

28. Lei, F.; Crow, W.T.; Kustas, W.P.; Dong, J.; Yang, Y.; Knipper, K.R.; Anderson, M.C.; Gao, F.; Notarnicola, C.; Greifeneder, F.; et al. Data assimilation of high-resolution thermal and radar remote sensing retrievals for soil moisture monitoring in a drip-irrigated vineyard. Remote Sens. Environ. 2020, 239, 111622. [CrossRef] [PubMed]

29. Khanal, S.; Fulton, J.; Shearer, S. An overview of current and potential applications of thermal remote sensing in precision agriculture. Comput. Electron. Agric. 2017, 139, 22-32. [CrossRef]

30. Messina, G.; Modica, G. Applications of UAV Thermal Imagery in Precision Agriculture: State of the Art and Future Research Outlook. Remote Sens. 2020, 12. [CrossRef]

31. Wagner, W.; Lemoine, G.; Rott, H. A Method for Estimating Soil Moisture from ERS Scatterometer and Soil Data. Remote Sens. Environ. 1999, 70, 191-207. [CrossRef]

32. Walker, J.P.; Willgoose, G.R.; Kalma, J.D. In situ measurement of soil moisture: A comparison of techniques. J. Hydrol. 2004, 293, 85-99. [CrossRef]

33. Rushton, K.R.; Eilers, V.H.M.; Carter, R.C. Improved soil moisture balance methodology for recharge estimation. J. Hydrol. 2006, 318, 379-399. [CrossRef]

34. Jones, H.G. Irrigation scheduling: Advantages and pitfalls of plant-based methods. J. Exp. Bot. 2004, 55, 2427-2436. [CrossRef]

35. Lobell, D.B.; Asner, G.P. Moisture Effects on Soil Reflectance. Soil Sci. Soc. Am. J. 2002, 66, 722-727. [CrossRef] 
36. Huang, S.; Ding, J.; Zou, J.; Liu, B.; Zhang, J.; Chen, W. Soil Moisture Retrival Based on Sentinel-1 Imagery under Sparse Vegetation Coverage. Sensors 2019, 19. [CrossRef] [PubMed]

37. Ben-Dor, E.; Chabrillat, S.; Demattê, J.A.M.; Taylor, G.R.; Hill, J.; Whiting, M.L.; Sommer, S. Using Imaging Spectroscopy to study soil properties. Remote Sens. Environ. 2009, 113, S38-S55. [CrossRef]

38. Peñuelas, J.; Gamon, J.A.; Fredeen, A.L.; Merino, J.; Field, C.B. Reflectance indices associated with physiological changes in nitrogen- and water-limited sunflower leaves. Remote Sens. Environ. 1994, 48, 135-146. [CrossRef]

39. Rapaport, T.; Hochberg, U.; Shoshany, M.; Karnieli, A.; Rachmilevitch, S. Combining leaf physiology, hyperspectral imaging and partial least squares-regression (PLS-R) for grapevine water status assessment. ISPRS J. Photogramm. Remote Sens. 2015, 109, 88-97. [CrossRef]

40. Dzikiti, S.; Verreynne, J.S.; Stuckens, J.; Strever, A.; Verstraeten, W.W.; Swennen, R.; Coppin, P. Determining the water status of Satsuma mandarin trees [Citrus Unshiu Marcovitch] using spectral indices and by combining hyperspectral and physiological data. Agric. For. Meteorol. 2010, 150, 369-379. [CrossRef]

41. Ihuoma, S.O.; Madramootoo, C.A. Recent advances in crop water stress detection. Comput. Electron. Agric. 2017, 141, 267-275. [CrossRef]

42. Bioucas-Dias, J.M.; Plaza, A.; Dobigeon, N.; Parente, M.; Du, Q.; Gader, P.; Chanussot, J. Hyperspectral Unmixing Overview: Geometrical, Statistical, and Sparse Regression-Based Approaches. IEEE J. Sel. Top. Appl. Earth Obs. Remote Sens. 2012, 5, 354-379. [CrossRef]

43. Liu, Y.; Liu, Y.; Chen, Y.; Zhang, Y.; Shi, T.; Wang, J.; Hong, Y.; Fei, T.; Zhang, Y. The Influence of Spectral Pretreatment on the Selection of Representative Calibration Samples for Soil Organic Matter Estimation Using Vis-NIR Reflectance Spectroscopy. Remote Sens. 2019, 11. [CrossRef]

44. Nawar, S.; Buddenbaum, H.; Hill, J.; Kozak, J.; Mouazen, A.M. Estimating the soil clay content and organic matter by means of different calibration methods of vis-NIR diffuse reflectance spectroscopy. Soil Tillage Res. 2016, 155, 510-522. [CrossRef]

45. Shi, T.; Wang, J.; Chen, Y.; Wu, G. Improving the prediction of arsenic contents in agricultural soils by combining the reflectance spectroscopy of soils and rice plants. Int. J. Appl. Earth Obs. Geoinf. 2016, 52, 95-103. [CrossRef]

46. Wang, J.; Ding, J.; Abulimiti, A.; Cai, L. Quantitative estimation of soil salinity by means of different modeling methods and visible-near infrared (VIS-NIR) spectroscopy, Ebinur Lake Wetland, Northwest China. PeerJ 2018, 6, e4703. [CrossRef]

47. Hong, Y.; Shen, R.; Cheng, H.; Chen, S.; Chen, Y.; Guo, L.; He, J.; Liu, Y.; Yu, L.; Liu, Y. Cadmium concentration estimation in peri-urban agricultural soils: Using reflectance spectroscopy, soil auxiliary information, or a combination of both? Geoderma 2019, 354, 113875. [CrossRef]

48. Hong, Y.; Chen, S.; Liu, Y.; Zhang, Y.; Yu, L.; Chen, Y.; Liu, Y.; Cheng, H.; Liu, Y. Combination of fractional order derivative and memory-based learning algorithm to improve the estimation accuracy of soil organic matter by visible and near-infrared spectroscopy. CATENA 2019, 174, 104-116. [CrossRef]

49. Lao, C.; Chen, J.; Zhang, Z.; Chen, Y.; Ma, Y.; Chen, H.; Gu, X.; Ning, J.; Jin, J.; Li, X. Predicting the contents of soil salt and major water-soluble ions with fractional-order derivative spectral indices and variable selection. Comput. Electron. Agric. 2021, 182, 106031. [CrossRef]

50. Hong, Y.; Guo, L.; Chen, S.; Linderman, M.; Mouazen, A.M.; Yu, L.; Chen, Y.; Liu, Y.; Liu, Y.; Cheng, H.; et al. Exploring the potential of airborne hyperspectral image for estimating topsoil organic carbon: Effects of fractional-order derivative and optimal band combination algorithm. Geoderma 2020, 365, 114228. [CrossRef]

51. Wang, X.; Zhang, F.; Kung, H.-t.; Johnson, V.C. New methods for improving the remote sensing estimation of soil organic matter content (SOMC) in the Ebinur Lake Wetland National Nature Reserve (ELWNNR) in northwest China. Remote Sens. Environ. 2018, 218, 104-118. [CrossRef]

52. Yang, P.; van der Tol, C.; Verhoef, W.; Damm, A.; Schickling, A.; Kraska, T.; Muller, O.; Rascher, U. Using reflectance to explain vegetation biochemical and structural effects on sun-induced chlorophyll fluorescence. Remote Sens. Environ. 2019, 231, 110996. [CrossRef]

53. Holzman, M.E.; Rivas, R.; Piccolo, M.C. Estimating soil moisture and the relationship with crop yield using surface temperature and vegetation index. Int. J. Appl. Earth Obs. Geoinf. 2014, 28, 181-192. [CrossRef]

54. Sandholt, I.; Rasmussen, K.; Andersen, J. A simple interpretation of the surface temperature/vegetation index space for assessment of surface moisture status. Remote Sens. Environ. 2002, 79, 213-224. [CrossRef]

55. Santos, W.J.R.; Silva, B.M.; Oliveira, G.C.; Volpato, M.M.L.; Lima, J.M.; Curi, N.; Marques, J.J. Soil moisture in the root zone and its relation to plant vigor assessed by remote sensing at management scale. Geoderma 2014, 221-222, 91-95. [CrossRef]

56. El-Hendawy, S.E.; Al-Suhaibani, N.A.; Elsayed, S.; Hassan, W.M.; Dewir, Y.H.; Refay, Y.; Abdella, K.A. Potential of the existing and novel spectral reflectance indices for estimating the leaf water status and grain yield of spring wheat exposed to different irrigation rates. Agric. Water Manag. 2019, 217, 356-373. [CrossRef]

57. Sims, D.A.; Gamon, J.A. Estimation of vegetation water content and photosynthetic tissue area from spectral reflectance: A comparison of indices based on liquid water and chlorophyll absorption features. Remote Sens. Environ. 2003, 84, 526-537. [CrossRef]

58. Van der Meer, F. The effectiveness of spectral similarity measures for the analysis of hyperspectral imagery. Int. J. Appl. Earth Obs. Geoinf. 2006, 8, 3-17. [CrossRef] 
59. Steinberg, A.; Chabrillat, S.; Stevens, A.; Segl, K.; Foerster, S. Prediction of Common Surface Soil Properties Based on Vis-NIR Airborne and Simulated EnMAP Imaging Spectroscopy Data: Prediction Accuracy and Influence of Spatial Resolution. Remote Sens. 2016, 8, 613. [CrossRef]

60. Metternicht, G.I.; Zinck, J.A. Remote sensing of soil salinity: Potentials and constraints. Remote Sens. Environ. 2003, 85, 1-20. [CrossRef]

61. Lary, D.J.; Alavi, A.H.; Gandomi, A.H.; Walker, A.L. Machine learning in geosciences and remote sensing. Geosci. Front. 2016, 7, 3-10. [CrossRef]

62. Nawar, S.; Mouazen, A.M. Predictive performance of mobile vis-near infrared spectroscopy for key soil properties at different geographical scales by using spiking and data mining techniques. CATENA 2017, 151, 118-129. [CrossRef]

63. Hassan-Esfahani, L.; Torres-Rua, A.; Jensen, A.; McKee, M. Assessment of Surface Soil Moisture Using High-Resolution MultiSpectral Imagery and Artificial Neural Networks. Remote Sens. 2015, 7. [CrossRef]

64. Jin, X.; Du, J.; Liu, H.; Wang, Z.; Song, K. Remote estimation of soil organic matter content in the Sanjiang Plain, Northest China: The optimal band algorithm versus the GRA-ANN model. Agric. For. Meteorol. 2016, 218-219, 250-260. [CrossRef]

65. Wang, X.; Zhang, F.; Ding, J.; Kung, H.-t.; Latif, A.; Johnson, V.C. Estimation of soil salt content (SSC) in the Ebinur Lake Wetland National Nature Reserve (ELWNNR), Northwest China, based on a Bootstrap-BP neural network model and optimal spectral indices. Sci. Total Environ. 2018, 615, 918-930. [CrossRef]

66. Chen, S.; Liang, Z.; Webster, R.; Zhang, G.; Zhou, Y.; Teng, H.; Hu, B.; Arrouays, D.; Shi, Z. A high-resolution map of soil pH in China made by hybrid modelling of sparse soil data and environmental covariates and its implications for pollution. Sci. Total Environ. 2019, 655, 273-283. [CrossRef]

67. Nawar, S.; Mouazen, A.M. On-line vis-NIR spectroscopy prediction of soil organic carbon using machine learning. Soil Tillage Res. 2019, 190, 120-127. [CrossRef]

68. Chen, S.; Martin, M.P.; Saby, N.P.A.; Walter, C.; Angers, D.A.; Arrouays, D. Fine resolution map of top- and subsoil carbon sequestration potential in France. Sci. Total Environ. 2018, 630, 389-400. [CrossRef]

69. Jia, Y.; Jin, S.; Savi, P.; Gao, Y.; Tang, J.; Chen, Y.; Li, W. GNSS-R Soil Moisture Retrieval Based on a XGboost Machine Learning Aided Method: Performance and Validation. Remote Sens. 2019, 11. [CrossRef]

70. Loggenberg, K.; Strever, A.; Greyling, B.; Poona, N. Modelling Water Stress in a Shiraz Vineyard Using Hyperspectral Imaging and Machine Learning. Remote Sens. 2018, 10, 202. [CrossRef]

71. Wu, T.; Luo, J.; Dong, W.; Sun, Y.; Xia, L.; Zhang, X. Geo-Object-Based Soil Organic Matter Mapping Using Machine Learning Algorithms With Multi-Source Geo-Spatial Data. IEEE J. Sel. Top. Appl. Earth Obs. Remote Sens. 2019, 12, 1091-1106. [CrossRef]

72. Tziachris, P.; Aschonitis, V.; Chatzistathis, T.; Papadopoulou, M. Assessment of spatial hybrid methods for predicting soil organic matter using DEM derivatives and soil parameters. CATENA 2019, 174, 206-216. [CrossRef]

73. Kou, Y.; Li, J.; Wang, Y.; Li, C.; Tu, B.; Yao, M.; Li, X. Scale-dependent key drivers controlling methane oxidation potential in Chinese grassland soils. Soil Biol. Biochem. 2017, 111, 104-114. [CrossRef]

74. Librán-Embid, F.; Klaus, F.; Tscharntke, T.; Grass, I. Unmanned aerial vehicles for biodiversity-friendly agricultural landscapes-A systematic review. Sci. Total Environ. 2020, 732, 139204. [CrossRef]

75. Barreto, M.A.P.; Johansen, K.; Angel, Y.; McCabe, M.F. Radiometric Assessment of a UAV-Based Push-Broom Hyperspectral Camera. Sensors 2019, 19. [CrossRef]

76. Pu, Y.; Zhou, J.; Yuan, X. Fractional Differential Mask: A Fractional Differential-Based Approach for Multiscale Texture Enhancement. IEEE Trans. Image Process. 2010, 19, 491-511. [CrossRef] [PubMed]

77. He, N.; Wang, J.-B.; Zhang, L.-L.; Lu, K. An improved fractional-order differentiation model for image denoising. Signal Process. 2015, 112, 180-188. [CrossRef]

78. Pu, Y.; Wang, W.; Zhou, J.; Wang, Y.; Jia, H. Fractional differential approach to detecting textural features of digital image and its fractional differential filter implementation. Sci. China Ser. F Inf. Sci. 2008, 51, 1319-1339. [CrossRef]

79. Hong, Y.; Liu, Y.; Chen, Y.; Liu, Y.; Yu, L.; Liu, Y.; Cheng, H. Application of fractional-order derivative in the quantitative estimation of soil organic matter content through visible and near-infrared spectroscopy. Geoderma 2019, 337, 758-769. [CrossRef]

80. Fu, C.; Gan, S.; Yuan, X.; Xiong, H.; Tian, A. Impact of Fractional Calculus on Correlation Coefficient between Available Potassium and Spectrum Data in Ground Hyperspectral and Landsat 8 Image. Mathematics 2019, 7, 488. [CrossRef]

81. Lin, X.; Su, Y.-C.; Shang, J.; Sha, J.; Li, X.; Sun, Y.-Y.; Ji, J.; Jin, B. Geographically Weighted Regression Effects on Soil Zinc Content Hyperspectral Modeling by Applying the Fractional-Order Differential. Remote Sens. 2019, 11, 636. [CrossRef]

82. Pande-Chhetri, R.; Abd-Elrahman, A. De-striping hyperspectral imagery using wavelet transform and adaptive frequency domain filtering. ISPRS J. Photogramm. Remote Sens. 2011, 66, 620-636. [CrossRef]

83. Zhou, W.; Bovik, A.C.; Sheikh, H.R.; Simoncelli, E.P. Image quality assessment: From error visibility to structural similarity. IEEE Trans. Image Process. 2004, 13, 600-612. [CrossRef]

84. Mittal, A.; Soundararajan, R.; Bovik, A.C. Making a “Completely Blind” Image Quality Analyzer. IEEE Signal Process. Lett. 2013, 20, 209-212. [CrossRef]

85. Yue, J.; Feng, H.; Yang, G.; Li, Z. A Comparison of Regression Techniques for Estimation of Above-Ground Winter Wheat Biomass Using Near-Surface Spectroscopy. Remote Sens. 2018, 10. [CrossRef] 
86. Tian, Y.C.; Yao, X.; Yang, J.; Cao, W.X.; Hannaway, D.B.; Zhu, Y. Assessing newly developed and published vegetation indices for estimating rice leaf nitrogen concentration with ground- and space-based hyperspectral reflectance. Field Crop. Res. 2011, 120, 299-310. [CrossRef]

87. Wang, J.; Ding, J.; Yu, D.; Ma, X.; Zhang, Z.; Ge, X.; Teng, D.; Li, X.; Liang, J.; Lizaga, I.; et al. Capability of Sentinel-2 MSI data for monitoring and mapping of soil salinity in dry and wet seasons in the Ebinur Lake region, Xinjiang, China. Geoderma 2019, 353, 172-187. [CrossRef]

88. Zhang, X.; Zhang, F.; Qi, Y.; Deng, L.; Wang, X.; Yang, S. New research methods for vegetation information extraction based on visible light remote sensing images from an unmanned aerial vehicle (UAV). Int. J. Appl. Earth Obs. Geoinf. 2019, 78, 215-226. [CrossRef]

89. Liang, Z.; Chen, S.; Yang, Y.; Zhou, Y.; Shi, Z. High-resolution three-dimensional mapping of soil organic carbon in China: Effects of SoilGrids products on national modeling. Sci. Total Environ. 2019, 685, 480-489. [CrossRef]

90. Chen, T.; Guestrin, C. Xgboost: A Scalable Tree Boosting System. In Proceedings of the 22nd ACM SIGKDD International Conference on Knowledge Discovery and Data Mining, San Francisco, CA, USA, 13 August 2016; pp. 785-794.

91. Galvão, R.K.H.; Araujo, M.C.U.; José, G.E.; Pontes, M.J.C.; Silva, E.C.; Saldanha, T.C.B. A method for calibration and validation subset partitioning. Talanta 2005, 67, 736-740. [CrossRef]

92. Nawar, S.; Mouazen, M.A. Comparison between Random Forests, Artificial Neural Networks and Gradient Boosted Machines Methods of On-Line Vis-NIR Spectroscopy Measurements of Soil Total Nitrogen and Total Carbon. Sensors 2017, 17. [CrossRef] [PubMed]

93. Chang, C.-W.; Laird, D.A.; Mausbach, M.J.; Hurburgh, C.R. Near-Infrared Reflectance Spectroscopy-Principal Components Regression Analyses of Soil Properties. Soil Sci. Soc. Am. J. 2001, 65, 480-490. [CrossRef]

94. Wetterlind, J.; Stenberg, B. Near-infrared spectroscopy for within-field soil characterization: Small local calibrations compared with national libraries spiked with local samples. Eur. J. Soil Sci. 2010, 61, 823-843. [CrossRef]

95. Terhoeven-Urselmans, T.; Vagen, T.-G.; Spaargaren, O.; Shepherd, K.D. Prediction of Soil Fertility Properties from a Globally Distributed Soil Mid-Infrared Spectral Library. Soil Sci. Soc. Am. J. 2010, 74, 1792-1799. [CrossRef]

96. Minasny, B.; Tranter, G.; McBratney, A.B.; Brough, D.M.; Murphy, B.W. Regional transferability of mid-infrared diffuse reflectance spectroscopic prediction for soil chemical properties. Geoderma 2009, 153, 155-162. [CrossRef]

97. Côté, J.-F.; Fournier, R.A.; Luther, J.E.; van Lier, O.R. Fine-scale three-dimensional modeling of boreal forest plots to improve forest characterization with remote sensing. Remote Sens. Environ. 2018, 219, 99-114. [CrossRef]

98. Tmušić, G.; Manfreda, S.; Aasen, H.; James, M.R.; Gonçalves, G.; Ben-Dor, E.; Brook, A.; Polinova, M.; Arranz, J.J.; Mészáros, J.; et al. Current Practices in UAS-based Environmental Monitoring. Remote Sens. 2020, 12. [CrossRef]

99. Jalilvand, E.; Tajrishy, M.; Ghazi Zadeh Hashemi, S.A.; Brocca, L. Quantification of irrigation water using remote sensing of soil moisture in a semi-arid region. Remote Sens. Environ. 2019, 231, 111226. [CrossRef]

100. Wang, J.; Shi, T.; Yu, D.; Teng, D.; Ge, X.; Zhang, Z.; Yang, X.; Wang, H.; Wu, G. Ensemble machine-learning-based framework for estimating total nitrogen concentration in water using drone-borne hyperspectral imagery of emergent plants: A case study in an arid oasis, NW China. Environ. Pollut. 2020, 266, 115412. [CrossRef]

101. Zhang, Z.; Ding, J.; Wang, J.; Ge, X. Prediction of soil organic matter in northwestern China using fractional-order derivative spectroscopy and modified normalized difference indices. CATENA 2020, 185, 104257. [CrossRef]

102. Xiaoping, W.; Fei, Z.; Hsiang-te, K.; Haiyang, Y. Spectral response characteristics and identification of typical plant species in Ebinur lake wetland national nature reserve (ELWNNR) under a water and salinity gradient. Ecol. Indic. 2017, 81, 222-234. [CrossRef]

103. Maimaitiyiming, M.; Ghulam, A.; Bozzolo, A.; Wilkins, J.L.; Kwasniewski, M.T. Early Detection of Plant Physiological Responses to Different Levels of Water Stress Using Reflectance Spectroscopy. Remote Sens. 2017, 9. [CrossRef]

104. Haboudane, D.; Miller, J.R.; Tremblay, N.; Zarco-Tejada, P.J.; Dextraze, L. Integrated narrow-band vegetation indices for prediction of crop chlorophyll content for application to precision agriculture. Remote Sens. Environ. 2002, 81, 416-426. [CrossRef]

105. Meng, X.; Bao, Y.; Liu, J.; Liu, H.; Zhang, X.; Zhang, Y.; Wang, P.; Tang, H.; Kong, F. Regional soil organic carbon prediction model based on a discrete wavelet analysis of hyperspectral satellite data. Int. J. Appl. Earth Obs. Geoinf. 2020, 89, 102111. [CrossRef]

106. Zheng, H.; Li, W.; Jiang, J.; Liu, Y.; Cheng, T.; Tian, Y.; Zhu, Y.; Cao, W.; Zhang, Y.; Yao, X. A Comparative Assessment of Different Modeling Algorithms for Estimating Leaf Nitrogen Content in Winter Wheat Using Multispectral Images from an Unmanned Aerial Vehicle. Remote Sens. 2018, 10. [CrossRef]

107. Gong, P.; Liu, H.; Zhang, M.; Li, C.; Wang, J.; Huang, H.; Clinton, N.; Ji, L.; Li, W.; Bai, Y.; et al. Stable classification with limited sample: Transferring a 30-m resolution sample set collected in 2015 to mapping 10-m resolution global land cover in 2017. Sci. Bull. 2019, 64, 370-373. [CrossRef]

108. Zhou, B.; Erell, E.; Hough, I.; Shtein, A.; Just, A.C.; Novack, V.; Rosenblatt, J.; Kloog, I. Estimation of Hourly near Surface Air Temperature Across Israel Using an Ensemble Model. Remote Sens. 2020, 12. [CrossRef]

109. He, M.; Kimball, J.S.; Running, S.; Ballantyne, A.; Guan, K.; Huemmrich, F. Satellite detection of soil moisture related water stress impacts on ecosystem productivity using the MODIS-based photochemical reflectance index. Remote Sens. Environ. 2016, 186, 173-183. [CrossRef]

110. Jin, X.; Kumar, L.; Li, Z.; Feng, H.; Xu, X.; Yang, G.; Wang, J. A review of data assimilation of remote sensing and crop models. Eur. J. Agron. 2018, 92, 141-152. [CrossRef] 
111. Sagan, V.; Maimaitijiang, M.; Sidike, P.; Eblimit, K.; Peterson, T.K.; Hartling, S.; Esposito, F.; Khanal, K.; Newcomb, M.; Pauli, D.; et al. UAV-Based High Resolution Thermal Imaging for Vegetation Monitoring, and Plant Phenotyping Using ICI 8640 P, FLIR Vue Pro R 640, and thermoMap Cameras. Remote Sens. 2019, 11. [CrossRef]

112. Deng, L.; Mao, Z.; Li, X.; Hu, Z.; Duan, F.; Yan, Y. UAV-based multispectral remote sensing for precision agriculture: A comparison between different cameras. ISPRS J. Photogramm. Remote Sens. 2018, 146, 124-136. [CrossRef]

113. Jay, S.; Baret, F.; Dutartre, D.; Malatesta, G.; Héno, S.; Comar, A.; Weiss, M.; Maupas, F. Exploiting the centimeter resolution of UAV multispectral imagery to improve remote-sensing estimates of canopy structure and biochemistry in sugar beet crops. Remote Sens. Environ. 2019, 231, 110898. [CrossRef] 